\title{
ANALYSIS AND TESTS OF REINFORCED CARBON-EPOXY/FOAM-CORE SANDWICH PANELS WITH CUTOUTS
}

\author{
Donald J. Baker \\ Vehicle Structures Directorate - ARL \\ NASA Langley Research Center \\ Hampton, VA 23681 \\ Charles Rogers \\ Bell Helicopter Textron, Inc. \\ Ft. Worth, TX 76101
}

\author{
Presented at the American Helicopter Society \\ 52nd Annual Forum \\ Washington, DC \\ June 4-6, 1996
}




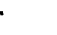




\section{ANALYSIS AND TESTS OF REINFORCED CARBON-EPOXY/FOAM- CORE SANDWICH PANELS WITH CUTOUTS}

\author{
Donald J. Baker * \\ Vehicle Structures Directorate - ARL \\ NASA Langley Research Center \\ Hampton, VA 23681
}

\author{
Charles Rogers \\ Bell Helicopter Textron, Inc. \\ Ft. Worth, TX 76101
}

\begin{abstract}
The results of a study of a low-cost structurallyefficient minimum-gage shear-panel design that can be used in light helicopters are presented. The shear-panel design is based on an integrally stiffened syntactic-foam stabilized-skin concept with an all-bias-ply tape construction for the skins. This sandwich concept is an economical way to increase the panel bending stiffness with a minimum weight penalty. The panels considered in the study were designed to be buckling resistant up to $100 \mathrm{lbs} / \mathrm{in}$. of shear load and to have an ultimate strength of $300 \mathrm{lbs} / \mathrm{in}$. The panel concept uses unidirectional carbon-epoxy tape on a syntactic adhesive as a stiffener that is co-cured with the skin and is an effective concept for improving panel buckling strength. The panel concept also uses pultruded carbon-epoxy rods embedded in a syntactic adhesive and over-wrapped with a bias-ply carbon-epoxy tape to form a reinforcing beam which is an effective method for redistributing load around a rectangular cutout. The buckling strength of the reinforced panels is 83 to 90 percent of the predicted buckling strength based on a linear buckling analysis. The maximum experimental deflection exceeds the maximum deflection predicted by a nonlinear analysis by approximately one panel thickness. The failure strength of the reinforced panels was two and a half to seven times the buckling strength. This efficient shear-panel design concept exceeds the required ultimate strength requirement of $300 \mathrm{lbs} / \mathrm{in}$ by more than 100 percent.
\end{abstract}

\section{Introduction}

\begin{abstract}
The present paper presents the results of a study of a low-cost structurally-efficient minimum-gage shear-panel design that can be used in minimum-gage structure such as a shear web in a keel or bulkhead in light helicopters. The panels are an integrally stiffened syntactic-foam stabilized-skin with an all-bias-ply tape construction for the skins. This sandwich concept is an economical way to increase the bending stiffness of the skin with a minimum weight penalty. The sandwich panels are reinforced with a stiffener that is co-cured with the skin. The minimumgage skin-stiffener design required consideration of panel strength and stability both with and without cutouts. Panel strength and stability is the main subject of the present paper and other design issues will be mentioned only to the extent required to understand the overall design requirements of the minimum-gage construction. The panels were designed to be buckling resistant up to $100 \mathrm{lbs} / \mathrm{in}$. of shear load and to have an ultimate strength of $300 \mathrm{lbs} / \mathrm{in}$. The present paper describes the results of the study, the buckling loads, and the postbuckled strength of the shear panels with and without a central rectangular cutout.
\end{abstract}

\section{Light Helicopter Design Approach}

A research and design study by Taylor, et al., (reference 1) attempted to apply lessons learned from past composite helicopter airframe programs to the design of a light helicopter airframe. This study described some unique material forms, structural concepts and fabrication methods necessary to produce affordable composite airframes that are competitive with metal construction for a future light helicopter. For the composite structures to be competitive with the aluminum design it is necessary to

\footnotetext{
- Aerospace Engineer, Structural Mechanics Branch.

Presented at the American Helicopter Society 52nd Annual Forum, Washington, DC, June 4-6, 1996.

Copyright $\odot 1996$ by the American Helicopter Society, Inc. All rights reserved.
} 
make large composite parts of simple laminates in a single cure step. All longerons utilized pultruded carbon-epoxy rods allowing easy placement along compound contoured paths.

Some major factors which govern the design of light helicopter airframes are: 1) selection of the minimumgage skin construction; 2) design of panel stiffeners that are integral to the panel and; 3 ) tool design where assembly interfaces are tool-side close-tolerance surfaces.

\section{Skin requirements}

The skin of a light helicopter airframe must be smooth, impervious to water, sufficiently durable to withstand impact and abrasion from the environment, and be able to carry the shear loads. Aluminum skins with thicknesses between 0.016 and 0.020 inches have these qualities. Since composite construction is layered, design is based on the available tape or fabric materials. Fabric can be obtained in thicknesses as small as 0.0075 inches, but one ply of fabric would not meet the design requirements. Tape material is available in three thicknesses, $0.0035,0.0055$, and 0.0075 inches. These thicknesses are not precise since the material is specified by weight per unit area and not by thickness. Four plies of 0.0075 -inch-thick material would be the minimum thickness considered to achieve a balanced lay-up and a porosity free laminate. For fabrication cost reasons, the thickest material is preferred, other considerations being equal.

Thus, both fabric and tape result in a minimum gage of about 0.030 inches in thickness. In order to minimize panel stiffening requirements from the understructure, a 0.030-inch-thick Syncore film adhesive is inserted at the mid-plane of the laminates which produces a "minisandwich" concept. This construction in carbon-epoxy composite materials weighs 0.318 pounds per square foot compared to the 0.233 pounds per square foot for a 0.016 inch-thick aluminum design. The greater unit weight of the composite design is offset by the reduced requirement for the understructure.

\section{Panel stiffening}

The most unique feature of the present panel design is the stiffener. To achieve the low-cost goals, it was essential that the stiffeners be laid-up and cured with the skin without the need for hard bag-side tooling. Stiffeners are typically angle shaped members where at least a portion of the stiffener is a web normal to the plane of the skin. To form such a part, and to hold it in position during cure, requires complex tooling and vacuum bagging fabrication concepts which have proven unreliable and labor intensive. Good section properties are achieved for the stiffener because of the height of the member. The stiffener concept selected for the present study is a flat sandwich member, generally 1.0-inch-wide, consisting of four layers of unidirectional tape on each side of an 0.080-inch-thick layer of Syncore adhesive. This member is laid up on the surface of the skin. This skin and stiffener concept is shown in figure 1 . When the stiffener is on the tool side of the skin, its shape is molded into the tool and the full geometry of the stiffener is maintained. When the stiffener is on the bag side of the skin, some section height is lost through flow of the Syncore adhesive from under the stiffener and along its edges. A molded bag would reduce this flow of the Syncore adhesive. Even so, the high modulus of the unidirectional carbon enables the achievement of the necessary stiffness without an excessive weight penalty.

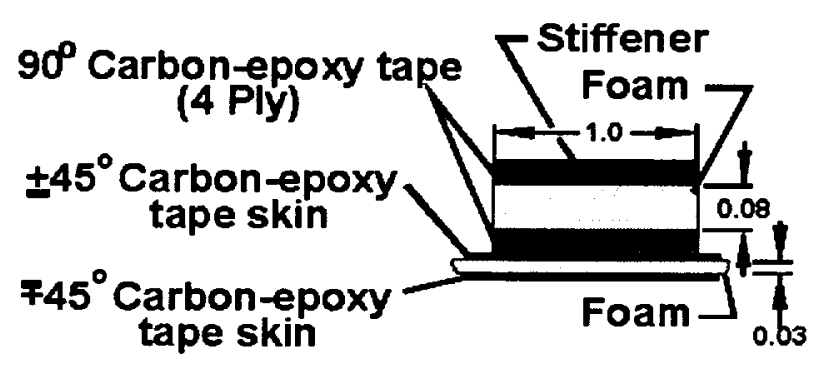

Figure 1. - Typical skin-stringer concept.

\section{Cutout design}

Openings through skins or webs are required for access to internal systems. Such cutout sizes may range from holes of 3-inches in diameter to holes of sufficient size for a man to enter. Cutouts in a metallic design are either circular or rectangular with large radii corners to minimize the stress concentration at the corners. An unexpected exceedance of the design loading condition might result in a higher-than-planned local stress, which is generally dissipated by local yielding of the metal. This local stress concentration may result in an eventual fatigue failure. Making an accurate determination of the threedimensional stresses around the curved portion of a cutout in a composite laminate is very difficult. In reality, the laminate is made of many layers of fibers and resin with several discrete local failure modes. Final failure is generally caused by fiber rupture in the continuous fibers tangent to the cutout edge. Stresses in these fibers are greatly altered during loading by microcracking, other local effects and laminate quality. An unexpected loading condition, combined with the brittle nature of composite materials, could result in a catastrophic failure.

The cutout design concept used in the present panels was developed by Bruhn (reference 2) for cutouts in tension field webs. Basically, the shear load in the cut fibers is transferred to a member acting as a beam and then redistributed to the remaining skin or web material. This load redistribution occurs on all four edges of the 
cutout. The corners of the cutout have a near-zero-value radius. In composite materials, local microcracking can relieve the local stress concentration that occurs in such sharp corners. The resulting design in composite materials is more robust and tolerant to unexpected loading condition and more easily fabricated than the normal or conventional pad-up design approach.

\section{Panel Design and Fabrication}

The structural concept for the minimum-gage carbonepoxy sandwich-skin panels has two 0.0075 -inch-thick plies of $\pm 45^{\circ}$ IM7/E7T1-2 carbon-epoxy unidirectional tape (Grade 190) on a 0.03-inch-thick HC9872 Syncore film adhesive. Two panel sizes were selected that could be tested using existing test fixtures. Three different types of panels were tested in this study. Eight-inch-square unreinforced panels of the minimum-gage sandwich skin design, were used to determine initial buckling and postbuckling strength of the mini-sandwich skin construction. These panels are identified as Panels A1 and $\mathrm{A} 2$ in the present paper. Four 13-inch-wide by 20 inch-long reinforced panels were used to determine the structural response of the stiffener concept and also to determine the effects of the cutouts on panel response. Two 13-inch-wide by 20 -inch-long panels have integral stiffeners as shown in figure 1 . The integral stiffeners are oriented in the direction of the 13-inch width and are equally spaced along the 20 -inch length of the panel. These panels are identified as Panels B1 and B2. Two 13inch-wide by 20 -inch-long panels (see figure 2 ) have the integral stiffeners shown in figure 1 , and a centrally located 3-inch-wide by 6-inch-long rectangular cutout. These panels are identified as Panels $\mathrm{Cl}$ and $\mathrm{C} 2$. The cutout is reinforced along the 6-inch-long side with 0.068 inch-diameter pultruded carbon-epoxy rods embedded in Syncore film adhesive and interlayered with bias-ply carbon-epoxy tape. This reinforcement extends to the middle of the bay past the end of the cutout and serves as the cutout edge reinforcement described in the previous paragraph. The stringer (figure 1) serves as the reinforcement at the end of the cutout.

A carbon-epoxy tool was used to fabricate the test panels. The rod-reinforced edge members along the side of the cutout (see figure 2) were laid into a recess in the tool. The stiffeners were placed on the bag side of the tool. The panels were manually laid up and cured in an autoclave for two hours at 80 psi pressure and $310^{\circ} \mathrm{F}$. The panels were cut to final size and oversize holes were drilled in the panels to match the test fixture. Steel loadintroduction tabs were secondarily bonded to the edges of each panel using a room temperature cure adhesive

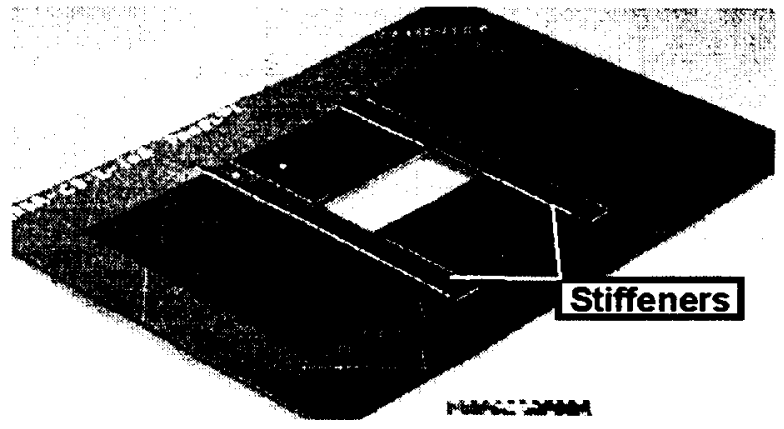

a) Shear test panel without loading tabs

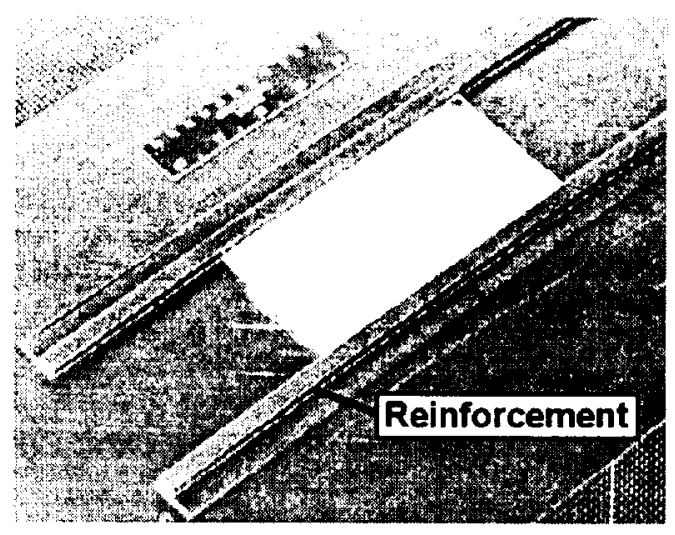

b) View of far side showing cutout reinforcement

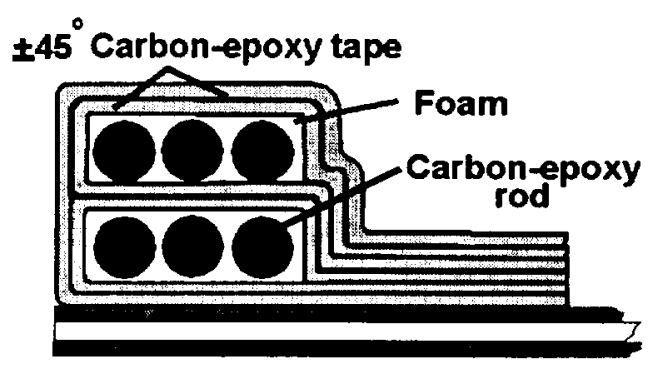

c) Cross-section of reinforcement along side of cutout

Figure 2. - Integrally stiffened shear test panel with a cutout.

Photomicrographs of sections taken from a panel with a cutout are shown in figures 3 and 4 . A cross-sectional view of the panel stiffener is shown in figure 3 . The effect of the stiffener located on the bag side of the panel is evident in the photographs. The panel core is reduced to a thickness of 0.016 inches under the stiffener and the core in the remainder of the panel is 0.03 -inches thick. The rounding of the stiffener and core washout is caused by the vacuum bag during the cure process. The final stiffener thicknesses are: 0.03 inches for the unidirectional 
carbon-epoxy material next to the bias-ply skin; 0.031 inches for the Syncore adhesive core; and 0.038 inches for the unidirectional carbon-epoxy material on the bottom surface. A photomicrograph of the reinforcement adjacent to the cutout is shown in figure 4 . This reinforcement was molded to shape by a recess in the tool. The pultruded

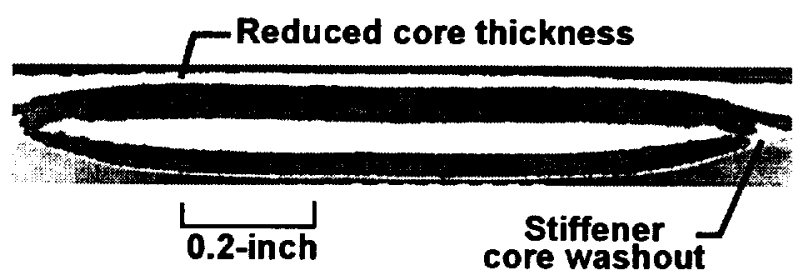

Figure 3. - Cross-sectional view of stringer on a panel with a cutout.

carbon rods are shown embedded in the Syncore film adhesive and interlayered with the bias-plies.

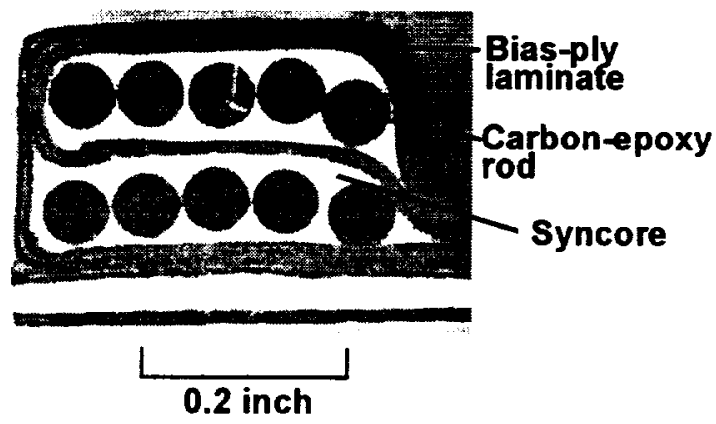

Figure 4. - Cross-sectional view of reinforcement along the side of the cutout.

\section{Test Procedure}

All test panels were instrumentated with back-to-back strain gages. The layout of the strain gages used for the 13-inch-wide by 20 -inch-long panels is shown in figure 5 . The panels with a cutout have 28 back-to-back strain gages ( 16 rosettes and 12 axial gages) located as shown in figure 5a. The panels without a cutout were instrumentated with 18 back-to-back strain gages ( 12 rosettes and 6 axial gages) located as shown in figure $5 \mathrm{~b}$. Out-of-plane displacements of the panels were determined by linear variable displacement transducers (LVDT) located as shown in figure 5 .

All specimen tests were performed at room temperature in the as-fabricated condition. The 8-inchsquare or 13 -inch-wide by 20 -inch-long shear test panels were installed in an in-plane shear test fixture (reference
3). The fixture and load introduction frame shown in figure 6 was installed in a hydraulic test machine which had adequate clearance between the testing-machine cross-heads to accept the fixture. Loads were applied at the rate of $1000 \mathrm{lbs} / \mathrm{min}$ or a shear load of $50 \mathrm{lbs} / \mathrm{in} / \mathrm{min}$ for the 13-inch-wide by 20-inch-long panels. Shadow moire interferometery was used to observe the out-ofplane deflections of the test panels. A video camera and a still camera recorded the changes in the moire fringe pattern. An apparatus shown in figure 7 was used to move the LVDT's with the fixture as it changed from a rectangle to a parallelogram, thus allowing the out-ofplane deflection of a point to be monitored as the test progressed. The load, strain, and out-of-plane displacements were recorded with a computer-controlled data acquisition system for each test.

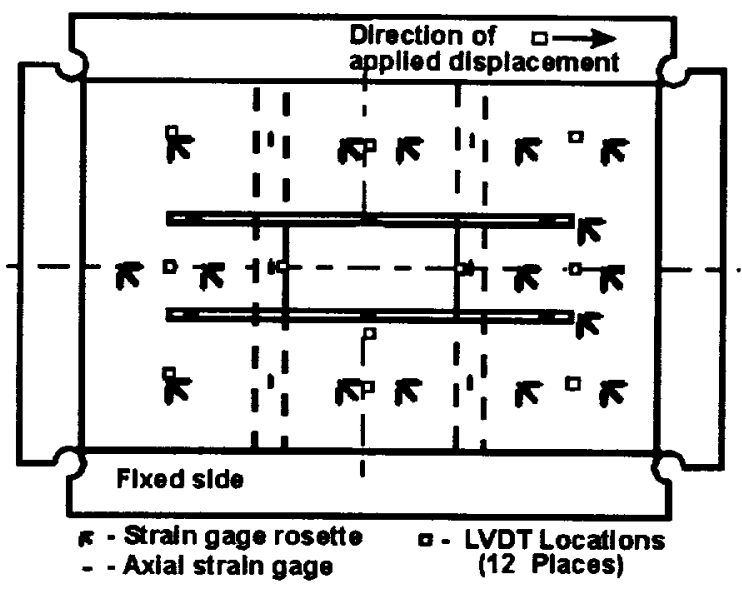

a.) Panel with a cutout.

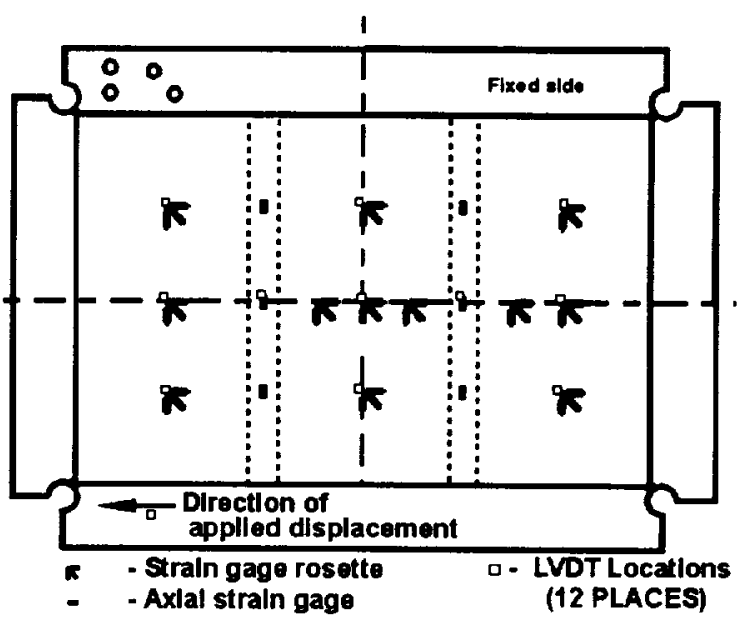

b.) Panel without a cutout.

Figure 5. - Location of strain gages and linear variable differential transducers (LVDT). 


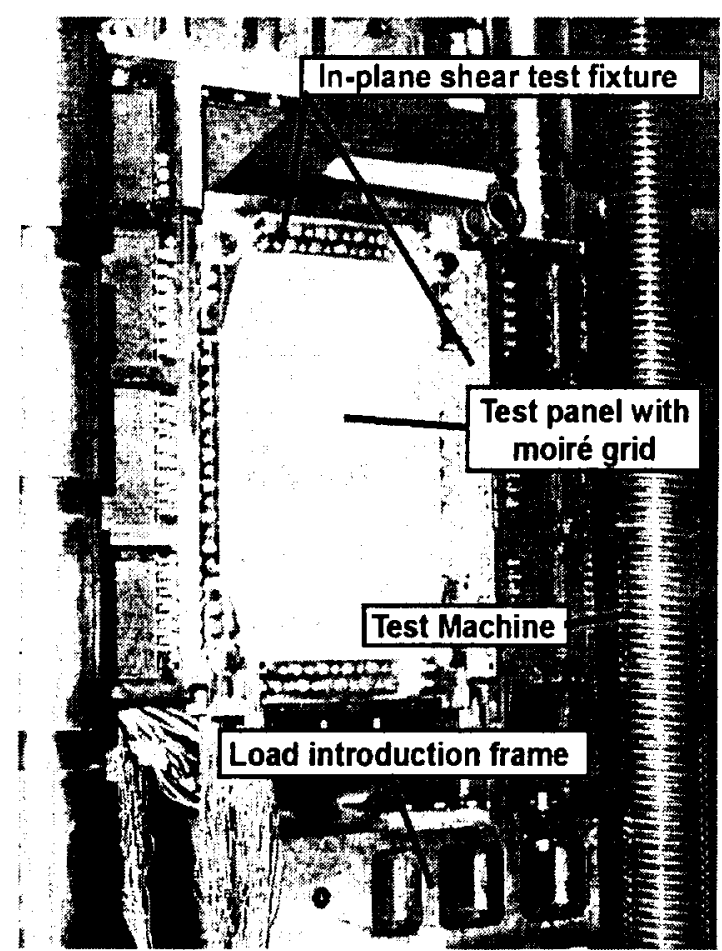

Figure 6. - Test setup with a panel installed.

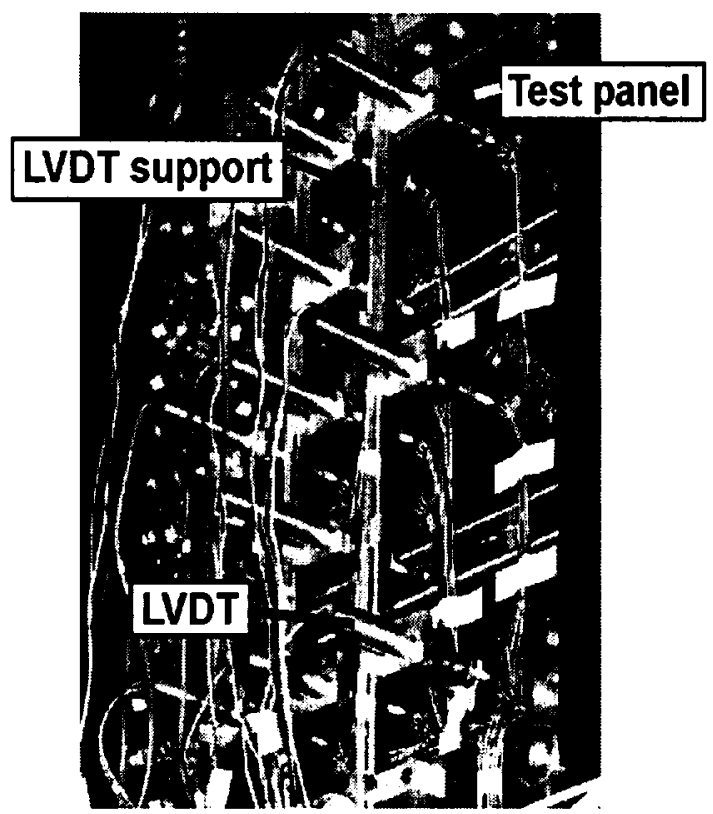

Figure 7. - Back side of test setup showing LVDT's.

\section{Analysis}

A finite element analysis was conducted for each design configuration using the STAGS nonlinear structural analysis code (reference 4) to determine the initial linear buckling load and geometrically nonlinear responses. STAGS is a finite element code for the general-purpose analysis of shell structures of arbitrary shape and complexity. The STAGS finite element model for the 13 -inch-wide by 20 -inch-long test panel with a cutout is shown in figure 8. A 9-node quadrilateral shell element, STAGS element 480 , was used in the analysis. The test fixture is also included in the model to provide the correct kinematics and boundary conditions for the test panels. The reinforcement along the side of the cutout was modeled as a layered plate where the pultruded carbon-epoxy rods and Syncore adhesive make up one layer. Similar finite element models were used for the 8 inch-square test panel and the 13-inch-wide by 20 -inchlong test panel without a cutout. The finite element analyses was conducted using the as-fabricated panel thicknesses previously noted.

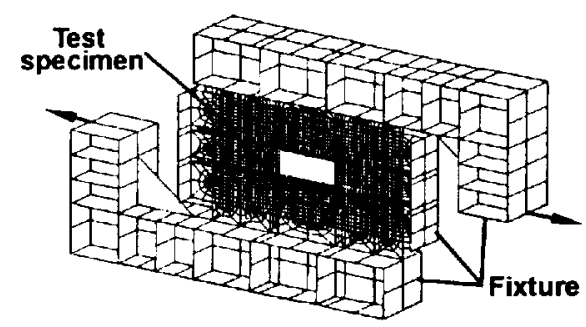

Figure 8. - Finite element model of a stiffened panel with a cutout.

\section{Experimental Results}

\section{Square test panel}

The buckle pattern for Panel A1 has three half-waves oriented at $45^{\circ}$ to the panel edge and is shown in figure 9 for a shear load of $940 \mathrm{lbs} / \mathrm{in}$. Results from back-to-back strain gage rosettes located in the center of Panel $\mathrm{Al}$ are shown in figure 10. The strains in the back-to-back gages are identical until the panel buckles at a load of 160 lbs/in. Loading of the panel was continued until failure occurred at $949 \mathrm{lbs} / \mathrm{in}$. Panel A2 indicated a similar response with an initial buckling load of $125 \mathrm{lbs} / \mathrm{in}$ and a 
postbuckling strength of $906 \mathrm{lbs} / \mathrm{in}$. A comparison of the out-of-plane deflections at the center of these two panels are shown in figure 11 and indicates a close similarity in their responses.

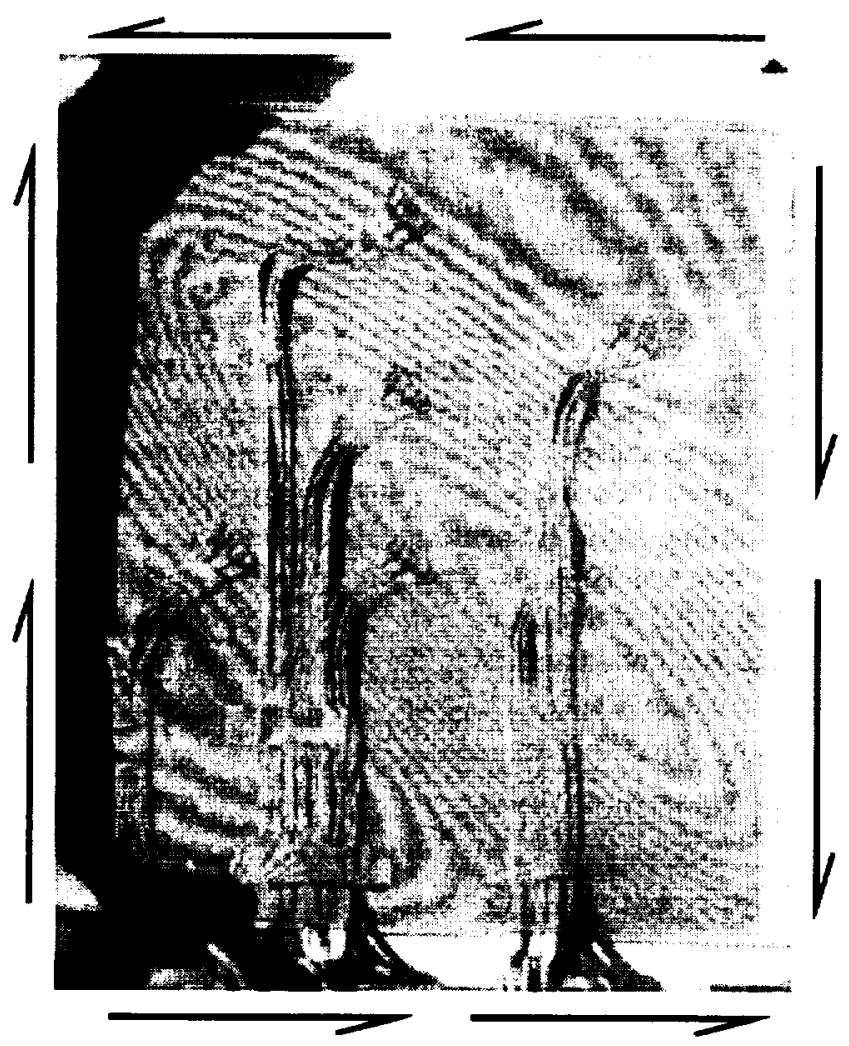

Figure 9. - Moiré fringe for Panel A1 at $\mathrm{N}_{\mathrm{xy}}=\mathbf{9 4 0}$ lbs/in.

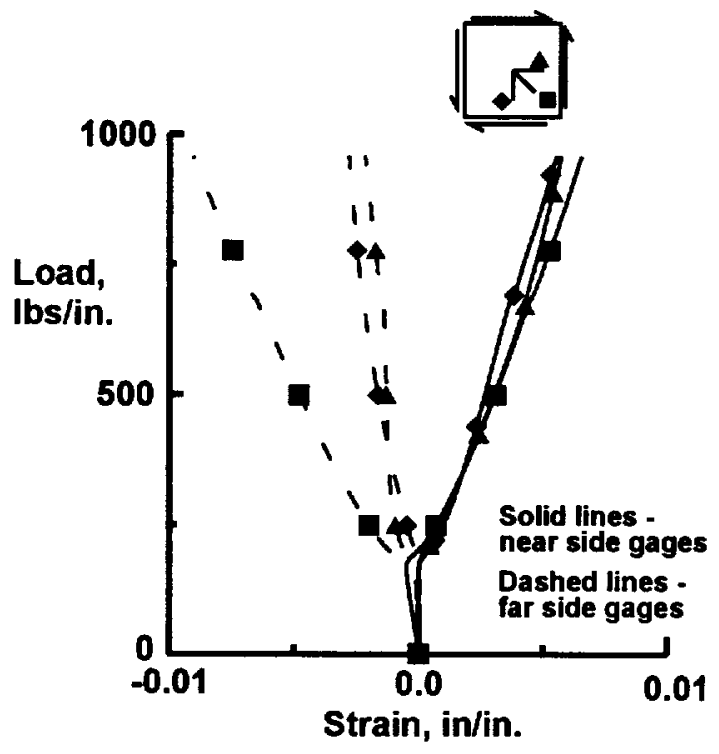

Figure 10. - Strain gage results for Panel A1.

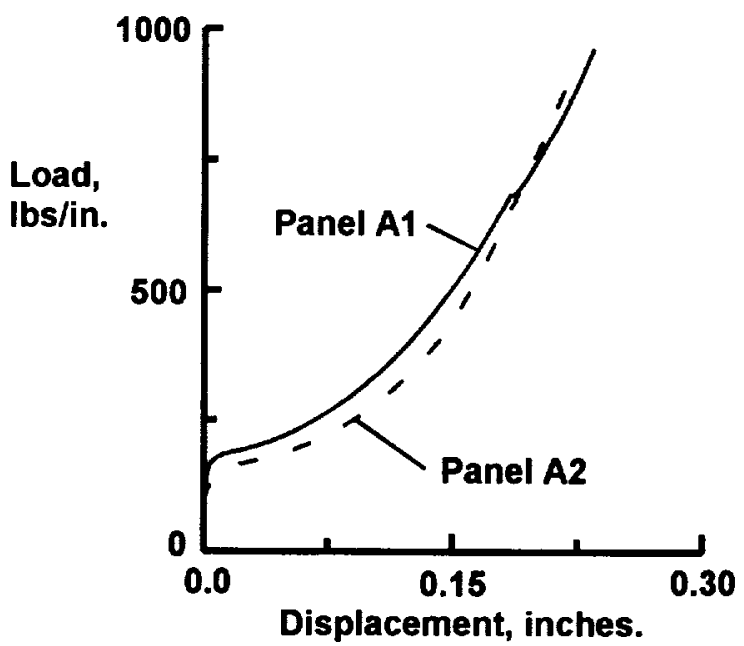

Figure 11. - Out-of-plane deflections at center of 8-inch-square panels.

\section{Panels without a cutout}

The buckle pattern for Panel B1 has four half waves and is shown in figure 12 for a load of $1104 \mathrm{lbs} / \mathrm{in}$. The buckle pattern is oriented at approximately $45^{\circ}$ to the edge of the test specimen. The effects of the stiffeners are indicated by irregularities in the moiré fringe pattern.

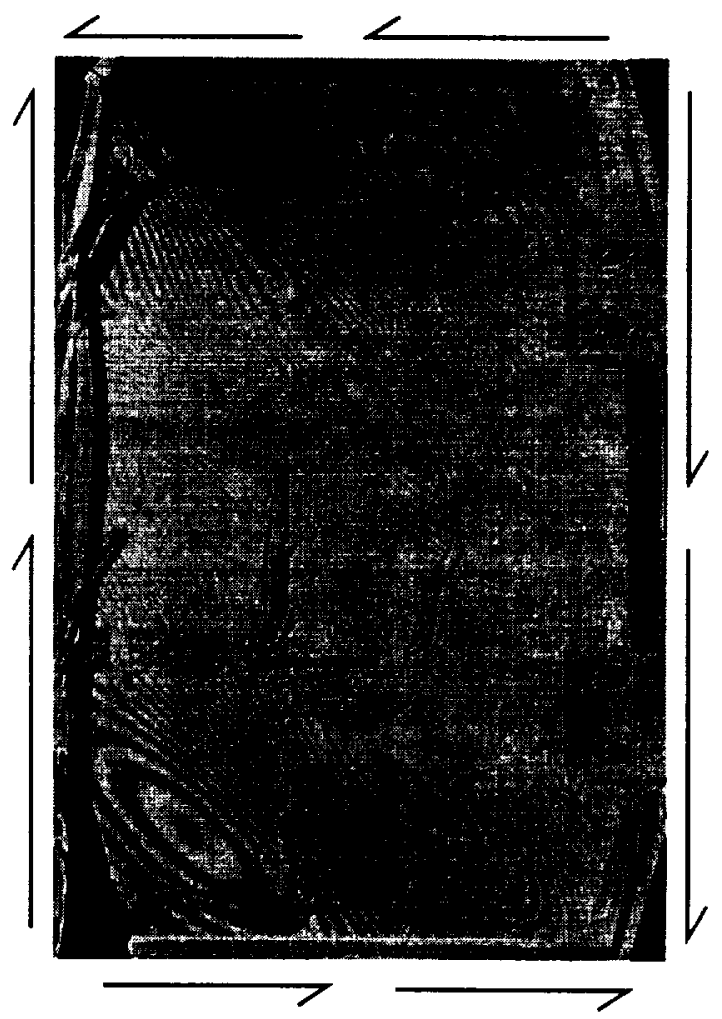

Figure 12. - Moiré fringe pattern of Panel B1 for $N_{x y}=1104$ lbs/in. 
The moiré fringe pattern for Panel B2 appeared identical to the pattern for Panel B1 for a similar load level. Strain results from a pair of back-to-back strain gage rosettes are shown in figure 13a for Panel B1 and in figure 13b for Panel B2. The strain reversal shown in figure 13a indicates that buckling occurs at $180 \mathrm{lbs} /$ in for Panel B1. The strain gages on Panel B2 (figure 13b) did not indicate a strain reversal at any load and continued to increase in

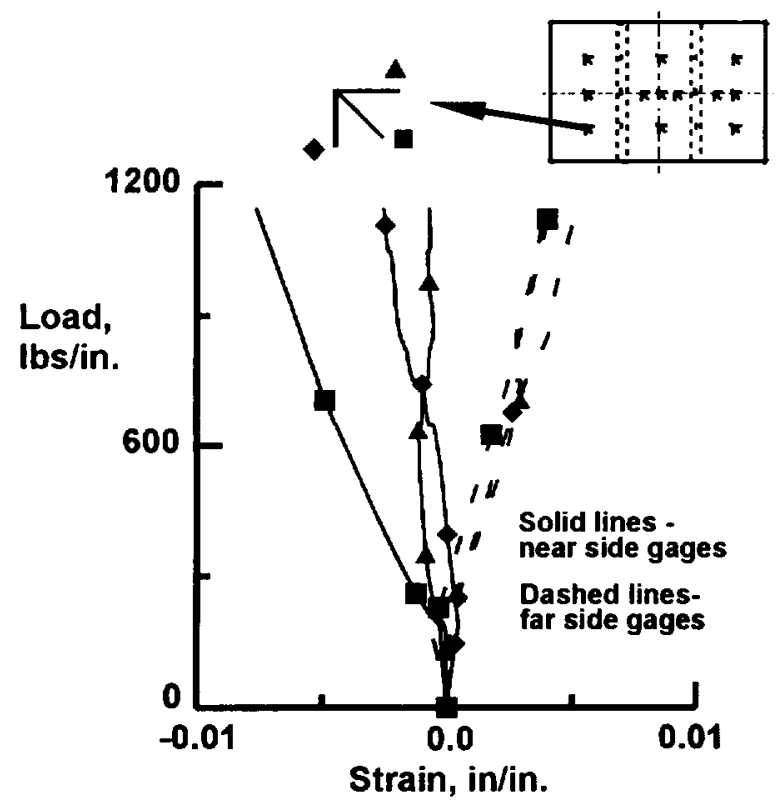

a.) Panel B1

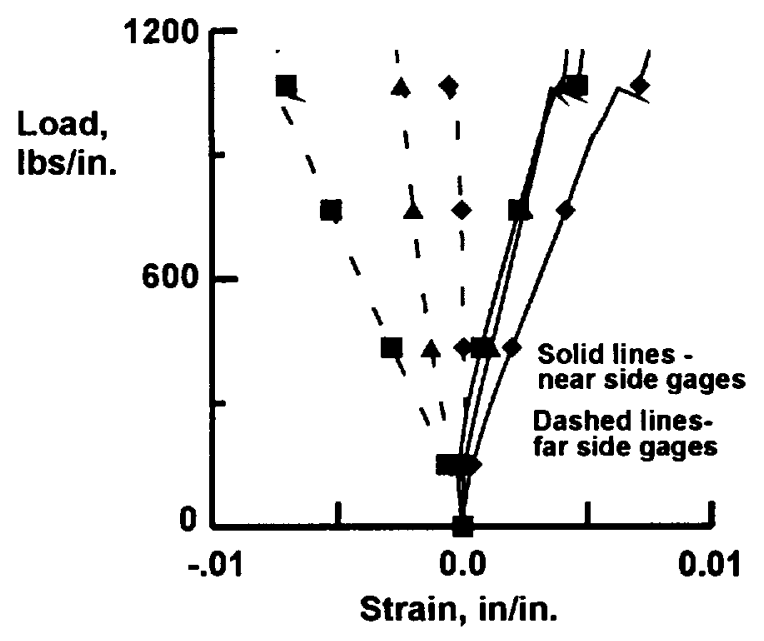

b.) Panel B2

Figure 13. - Strain gage results at a point on panels without a cutout. magnitude until failure of the panel. Comparison of the strain gage results, shown in figures $13 \mathrm{a}$ and $13 \mathrm{~b}$, from like gages on the two panels shows that the strains are of opposite sign of each other which indicates the panels deflected in opposite directions. For example, the nearside gage denoted by the diamond is in compression on Panel B1 and the same gage is in tension on Panel B2. The differences in direction of the deflections is verified in figure 14 which shows a plot of the out-of-plane

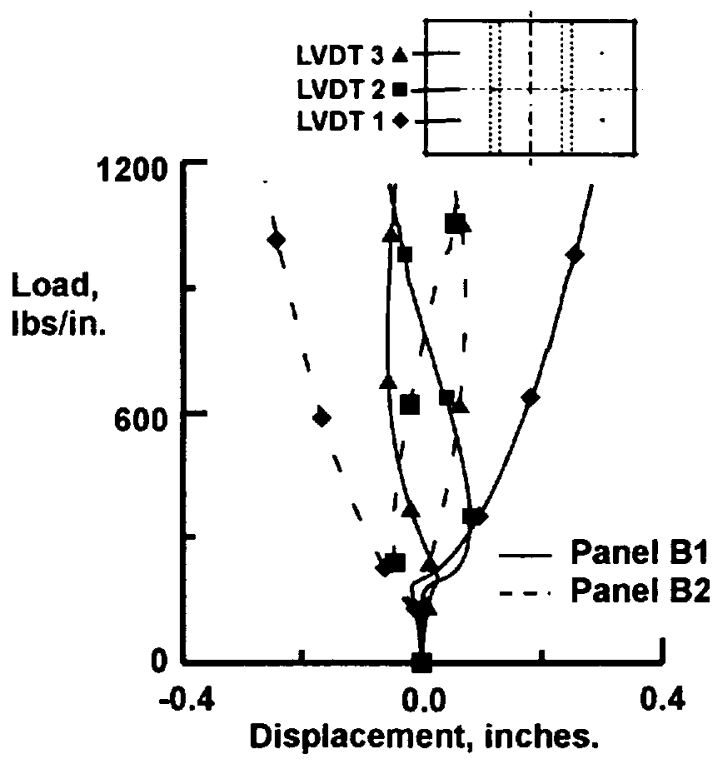

Figure 14.- Out-of-plane displacements in panels without a cutout.

displacements at three locations across one end of the panel. The out-of-plane deflections at the location of LVDT 1 on Panel B1 is negative while the displacements at the same location on Panel B2 is positive. The other two LVDT's shown in figure 14 also deflect in opposite directions. The out-of-plane displacement for a point on the stiffener at the centerline of the panel is shown in figure 15. Panel B1 deflects out-of-plane in the positive direction after buckling to a magnitude of approximately 0.3 inches at failure. The deflection at this point on Panel B2 is in the opposite direction from Panel B1. The load at which the stiffener on Panel B2 started to deform out-ofplane is $125 \mathrm{lbs} / \mathrm{in}$ which could be considered the buckling load for this panel. This change of out-of-plane deflection direction is evident for all strain gage and LVDT locations. A comparison of the test-machine cross-head displacement for both panels is shown in figure 16. The deflections are the same for both panels indicating that the panels have the same in-plane shear stiffness. A photograph of the failed Panel B2 is shown in figure 17. The panel failed in diagonal directions at various places in 


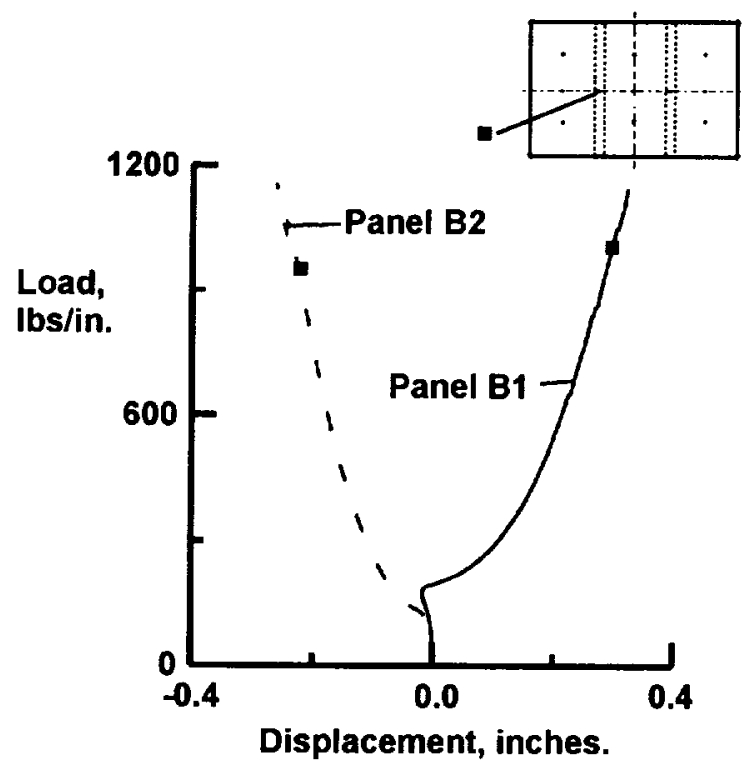

Figure 15. - Out-of-plane displacements in panels without a cutout.

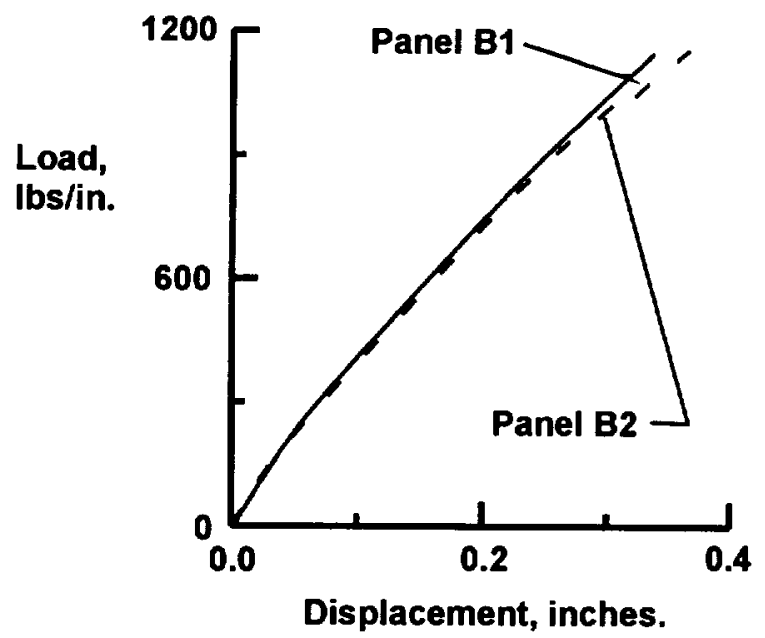

Figure 16. - Comparison of test-machine crosshead displacements for panels without a cutout.

the skin as would be expected of a panel in diagonal tension. The failure characteristics of Panel B1 and Panel B2 are similar. Panel B1 failed at $1130 \mathrm{lbs} / \mathrm{in}$ and Panel B2 failed at $1139 \mathrm{lbs} / \mathrm{in}$.

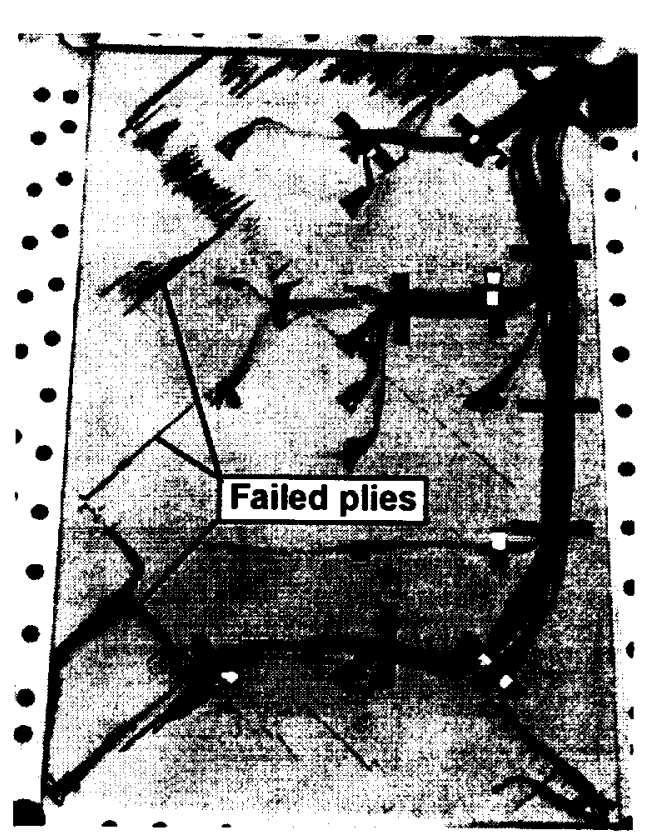

a) Side with moiré grid

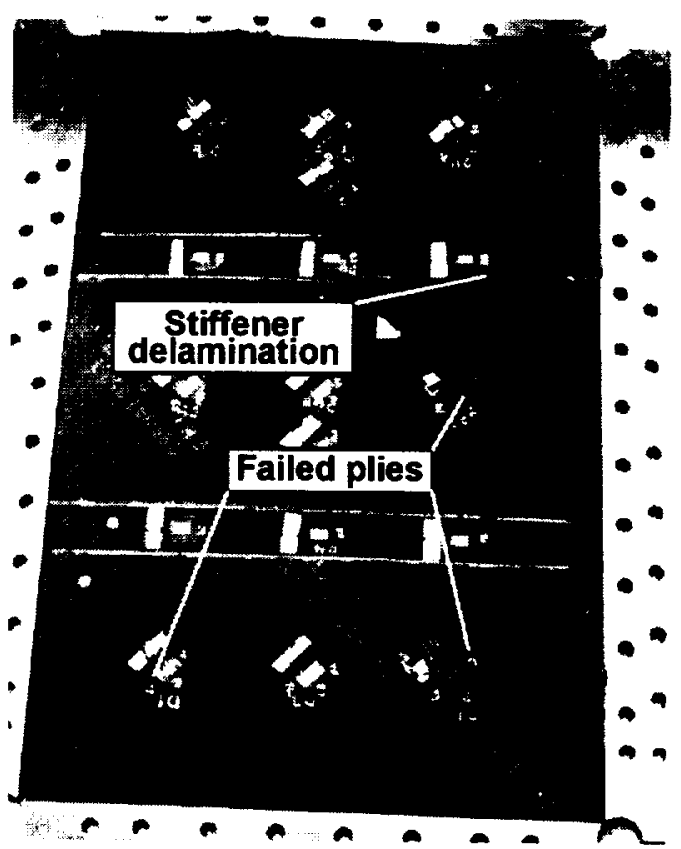

b) Back side

Figure 17. - Failed Panel B2.

\section{Panels with a cutout}

The buckling patterns for Panel Cl with $\mathrm{N}_{\mathrm{xy}}=402$ $\mathrm{lbs} / \mathrm{in}$ and for Panel C2 with $\mathrm{N}_{\mathrm{xy}}=376 \mathrm{lbs} / \mathrm{in}$ are shown in figures 18 and 19, respectively. The buckle pattern for Panel C1 (figure 18) has two half-waves in the bays between the stiffeners and the top and bottom edges of the panel. The orientation of one half-wave of the buckle pattern is approximately $30^{\circ}$ to the bottom edge of the 


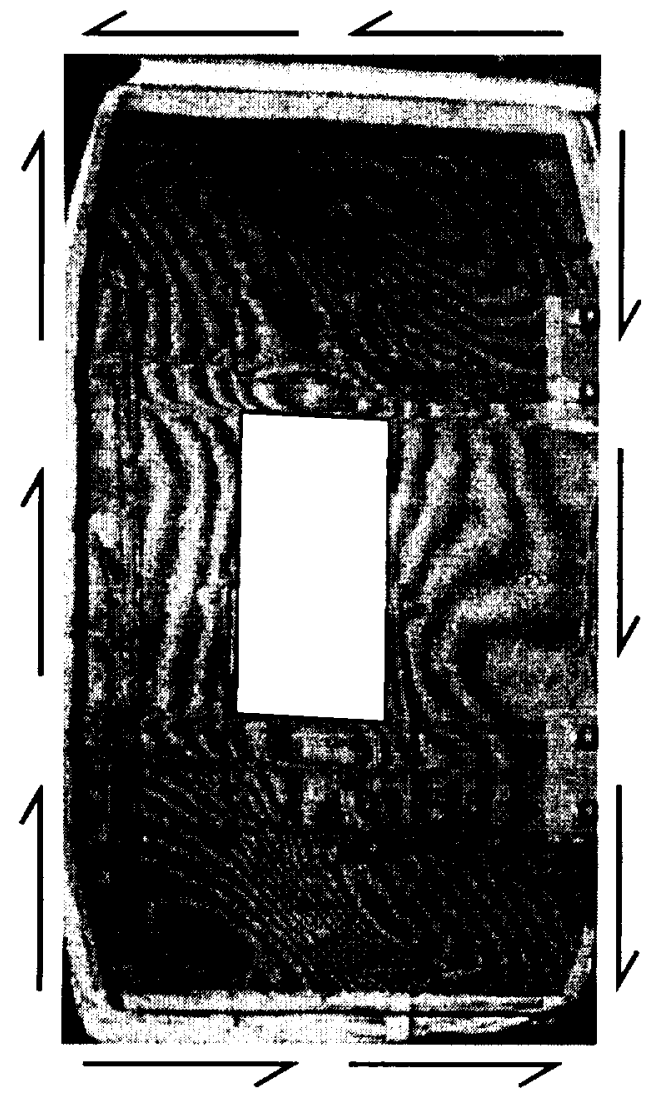

Figure 18. - Moiré fringe pattern for Panel C1 at $N_{x y}=402 \mathrm{lbs} / \mathrm{in}$.

panel and the orientation of the other half-wave is approximately $45^{\circ}$ to the bottom edge of the panel. Panel C2 (figure 19) has one half-wave oriented at approximately $45^{\circ}$ to the bottom edge of the panel and a second wave is developing in the corner at the top and bottom of the panel. The effect of the stiffeners can be observed from the changes in the moiré fringe pattern at the stiffener locations. The effect of the beam reinforcements parallel to the long side of the cutout does not appear in the moiré fringe patterns. The panels deformed out-of-plane when the loading was initiated and continued to deform until failure. Strain gage results for two pairs of back-to-back strain gage rosettes on Panel C1 are shown in figure 20 . The results from strain gages at location $\mathrm{A}$ in the center of a bay between the stringer and the reinforcement termination are shown in figure $20 \mathrm{a}$. The results from strain gages at location $B$ on the panel centerline midway between the reinforcement termination and the end of the panel are shown in figure 20b. Backto-back strain gages denoted by the diamond symbol and the triangle symbol at Location A (figure 20a) indicate the same value of strain until approximately $220 \mathrm{lbs} / \mathrm{in}$ when the results for these gages change slope. The results for

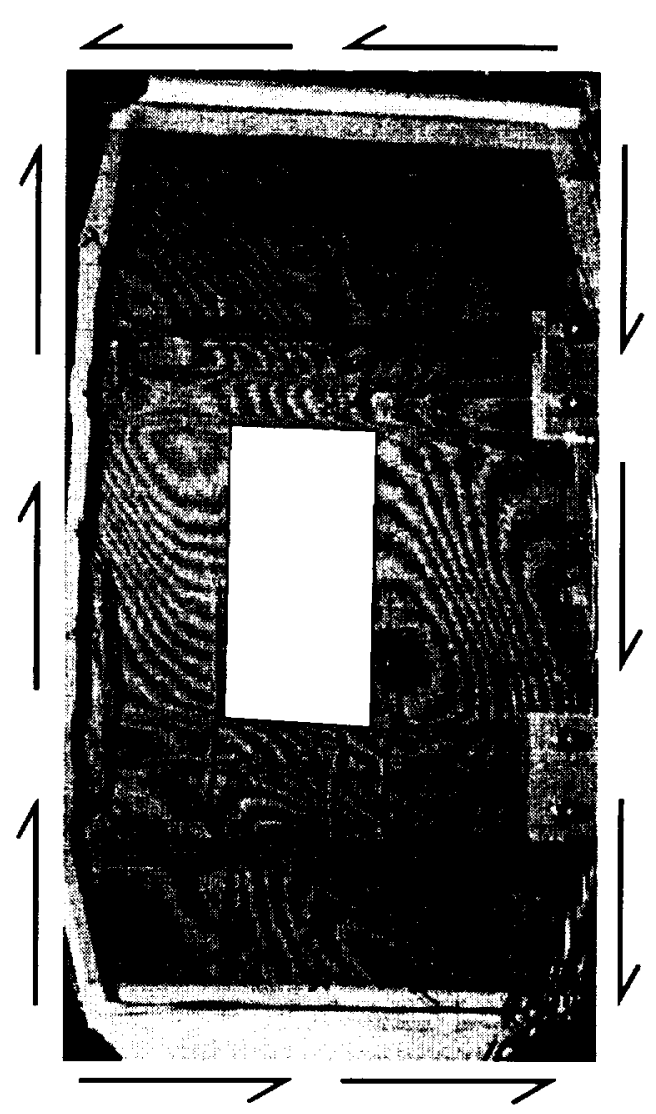

Figure 19. - Moiré fringe pattern for Panel C2 at $\mathbf{N}_{\mathbf{x y}}=376 \mathrm{lbs} / \mathrm{in}$.

strain gages denoted by the circle symbol and the cross symbol at Location B (figure 20b) also change slope at $220 \mathrm{lbs} / \mathrm{in}$. Strain gage results from two pair of back-toback strain gages rosettes on Panel $\mathrm{C} 2$ are shown in figure 21 . The strains shown in figures $21 \mathrm{a}$ and $21 \mathrm{~b}$ follow the same trends as for Panel Cl (figure 20) but have lower magnitudes. The results for strain gages denoted by a circle symbol and a cross symbol indicates a change of slope at approximately $280 \mathrm{lbs} / \mathrm{in}$. A comparison of the out-of-plane displacements at three locations across the end of the panel are shown in figure 22. LVDT 1 and LVDT 2 have the same trends for both of the panels. Displacements for LVDT 3 (triangle symbol) are in the opposite directions for each panel. Strain gage results for rosettes near LVDT 3 do not indicate significant differences in the results for the two panels. A comparison of the out-of-plane displacements at two locations around the cutout are shown in figure 23.

LVDT 4 is located on the stiffener at the centerline of the panel and LVDT 5 is located on the beam reinforcement at the centerline of the panel. The out-of-plane deflection for the panels measured by LVDT 4 (diamond symbol) is in different directions for the panels. The out-of-plane 


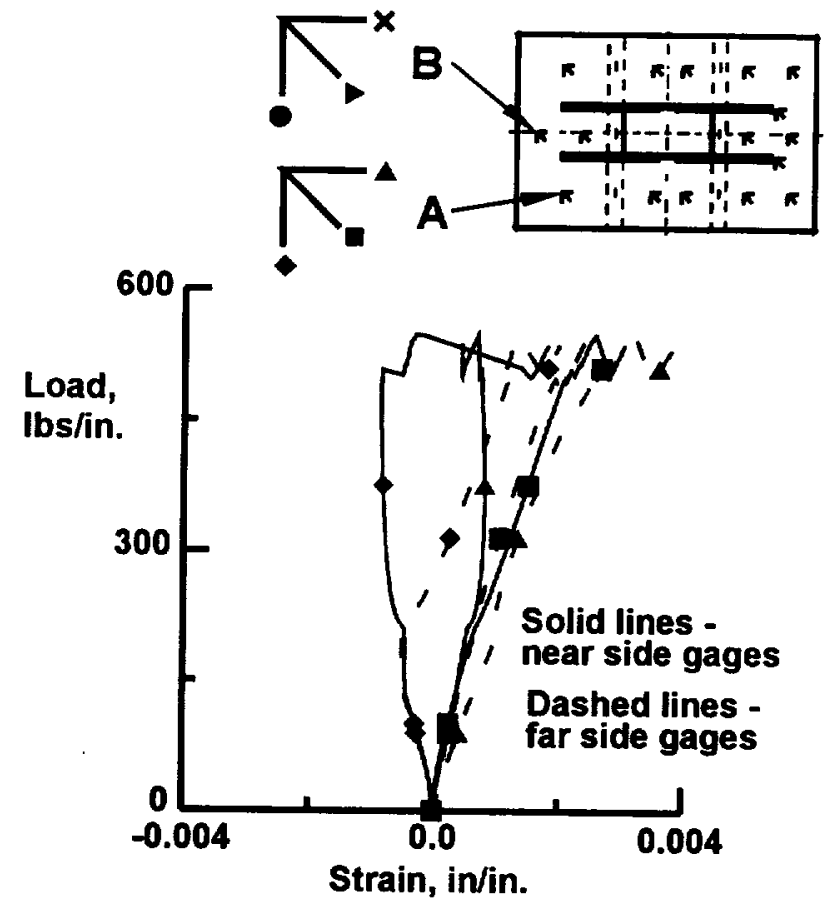

a.) Location $A$

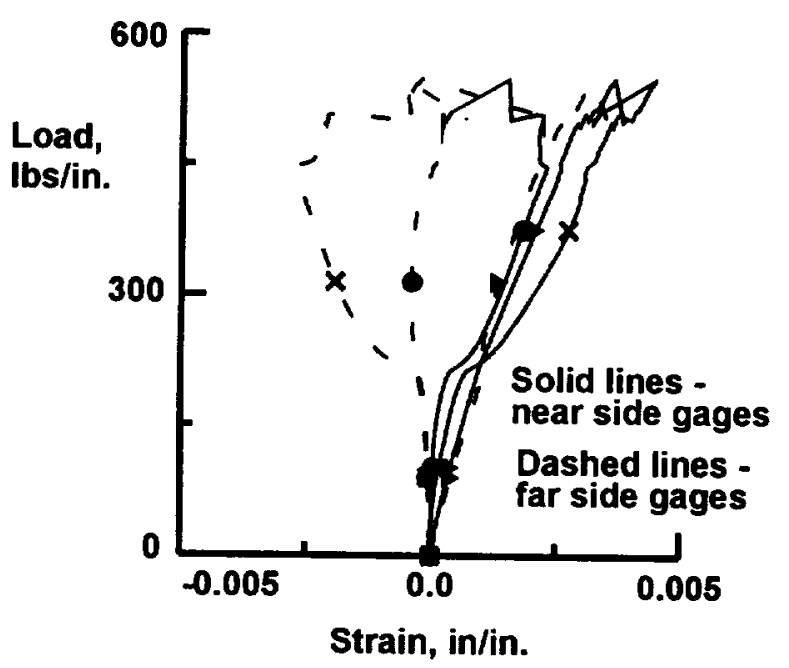

b.) Location B

Figure 20. - Strain gage results at two locations on panel C1.

deflection at the location of LVDT 5 is the same for both panels. A comparison of the test-machine cross-head displacement is shown in figure $\mathbf{2 4}$ for both panels. The initial cross-head deflection is the same for both panels indicating that the in-plane shear stiffnesses for the panel are nearly equal.

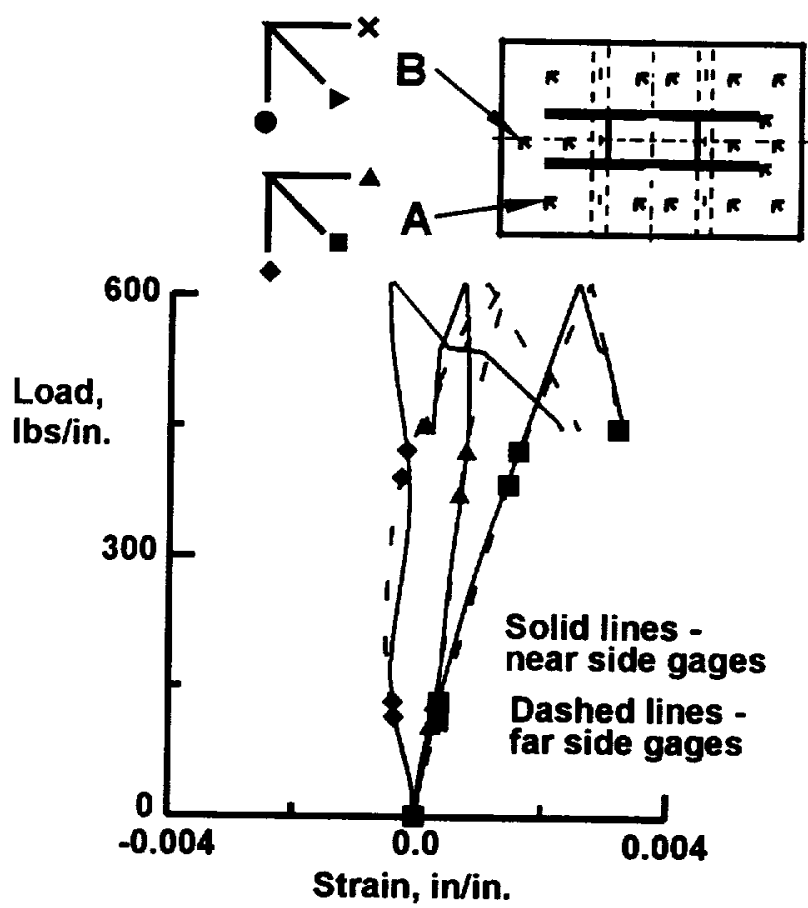

a.) Loaction $A$

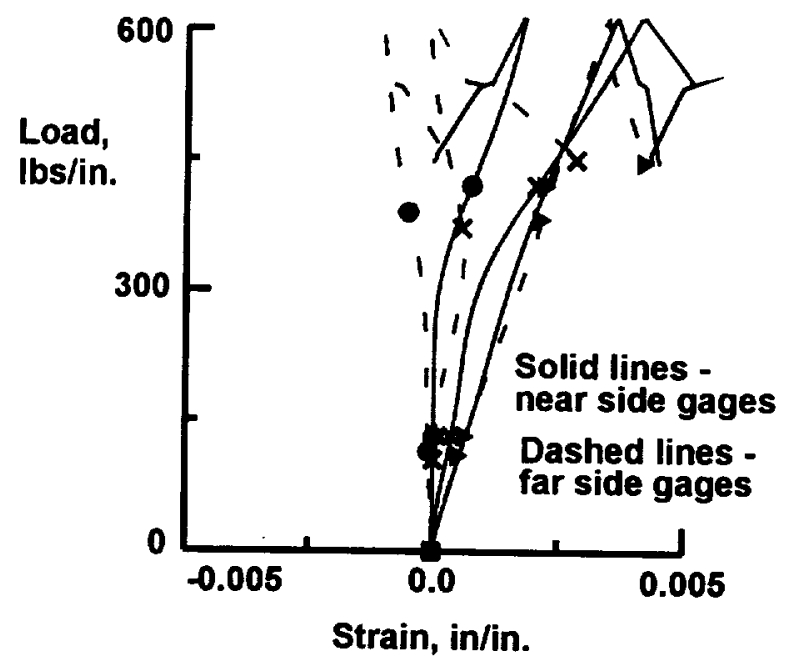

b.) Location $B$

Figure 21. - Strain gage results at two locations on Panel C2.

Panel $\mathrm{C} 1$ failure initiated at approximately $500 \mathrm{lbs} / \mathrm{in}$ and grew progressively as observed in figure $20 \mathrm{a}$ by the variations in load and strain near the maximum load. The failed Panel $\mathrm{Cl}$ is shown in figure 25 and the progressive nature of multiple fractures is indicated by the splintering at the ends of the beam reinforcement. The layers of carbon-epoxy material were pulled apart and pulled from 


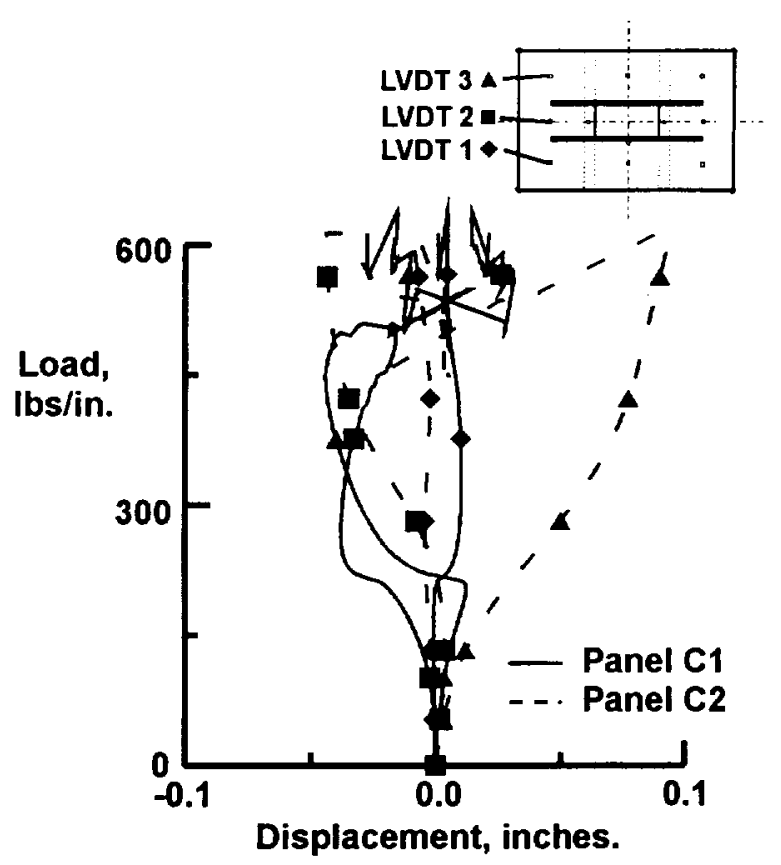

Figure 22 - Out-of-plane deflections for panels with a cutout.

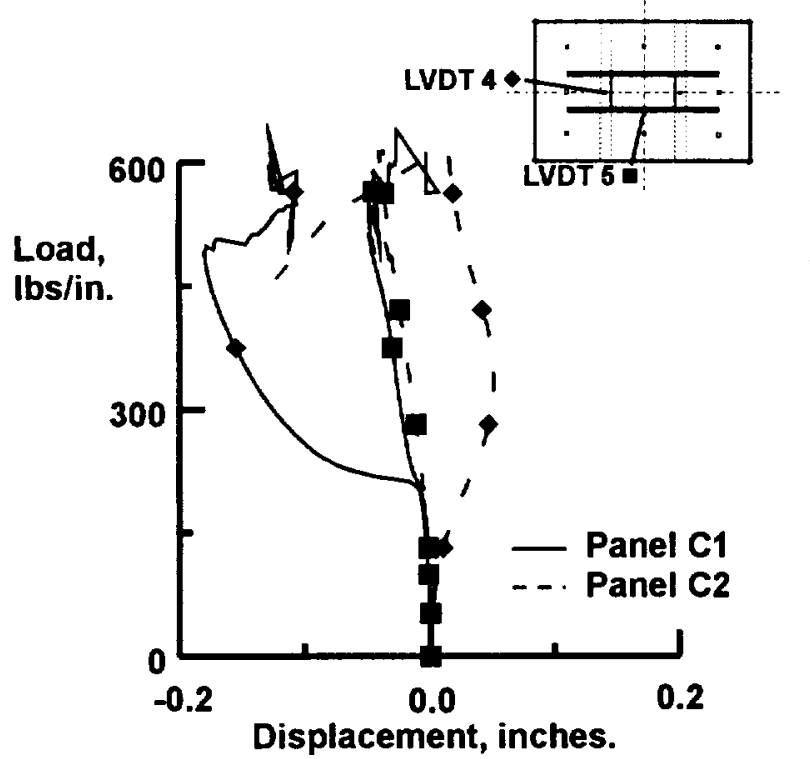

Figure 23. - Out-of-plane deflections around cutout in panels.

the core at the ends of the beam reinforcement. A stiffener was also locally delaminated from the skin. The maximum load for Panel C1 failure was $629 \mathrm{lbs} / \mathrm{in}$. Panel C2 did not exhibit a progressive failure mode similar to Panel C1. Panel C2 was loaded to a maximum load 605 lbs/in when failure occurred. A single rupture in the skin

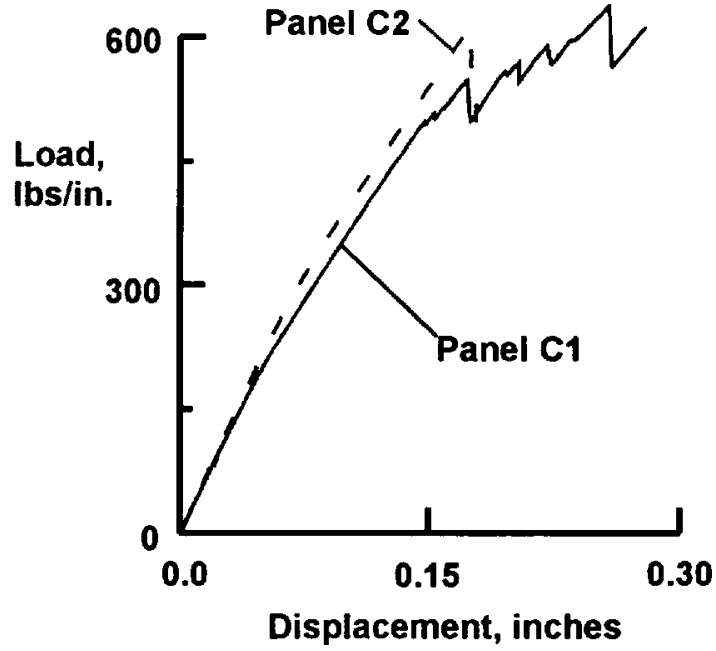

Figure 24. - Comparison of test-machine crosshead displacements for panels with a cutout.

occurred, which is orientated at $45^{\circ}$ to the panel edge and intersects the end of the beam reinforcement.

\section{Analytical Results}

\section{Square test panel}

The predicted linear buckling load for the 8-inchsquare test panel is $270 \mathrm{lbs} / \mathrm{in}$. The predicted out-of-plane displacement results, $w$, from a nonlinear STAGS analysis of the mini-sandwich panel are shown in figure 26 for $N_{x y}$ $=1000 \mathrm{lbs} / \mathrm{in}$. This load is approximately four times the predicted linear buckling load. The nonlinear analysis predicts three half-waves oriented at $45^{\circ}$ to the side of the panel as shown in figure 26 for a load of $1000 \mathrm{lbs} / \mathrm{in}$. The predicted out-of-plane displacements vary from -0.05 to 0.17 inches in magnitude.

\section{Panel without a cutout}

The finite element model used for the panel without a cutout is the same as the model shown in figure 8 except the cutout is filled with elements. The predicted buckling load from the linear analysis is $180 \mathrm{lbs} / \mathrm{in}$. The predicted mode shape from the linear buckling analysis has four half-waves for the first mode and is shown in figure 27. The predicted out-of-plane displacement results, $w$, from a nonlinear STAGS analysis of the panel are shown in figure 28 for $N_{x y}=1000 \mathrm{lbs} / \mathrm{in}$. The nonlinear analysis predicts four half-waves oriented at approximately $45^{\circ}$ to the side of the panel with another half-wave starting to appear at two corners as shown in figure 28 for a load of $1000 \mathrm{lbs} / \mathrm{in}$. The effect of the stiffeners are indicated by the irregularities in the shape of two of the predicted 
fringe patterns. The predicted out-of-plane displacements vary from -0.23 inches to 0.21 inches in magnitude.

A linear STAGS analysis was performed on the flat panel without stiffeners to help determine the effect of the stiffeners on the buckling load. The buckling load for the unstiffened panel determined by the linear analysis is 81 lbs/in. The flat stiffeners on the sandwich panel increased the buckling load by 220 percent.

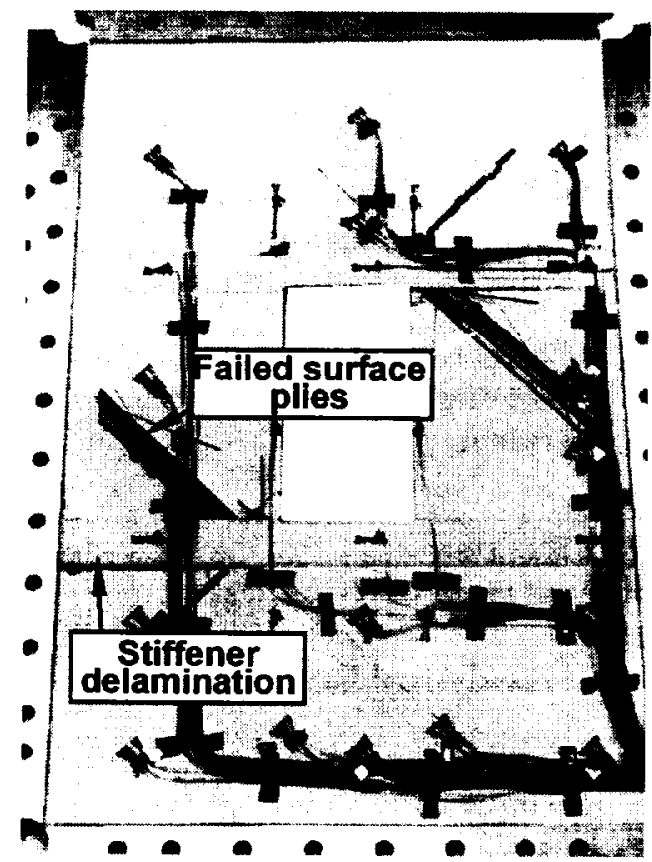

a) Side with moiré grid

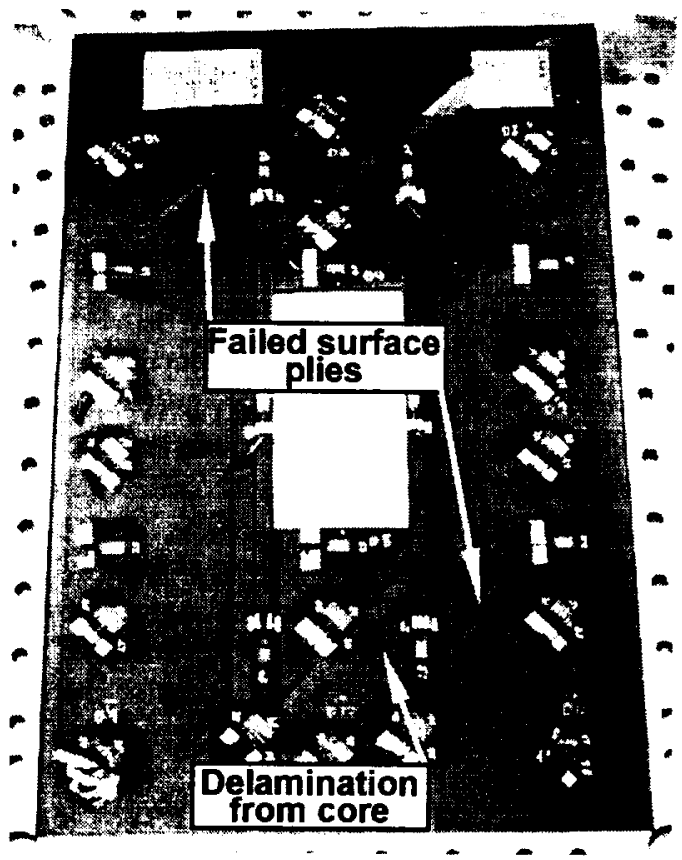

b) Back side

Figure 25. - Failed Panel C1.

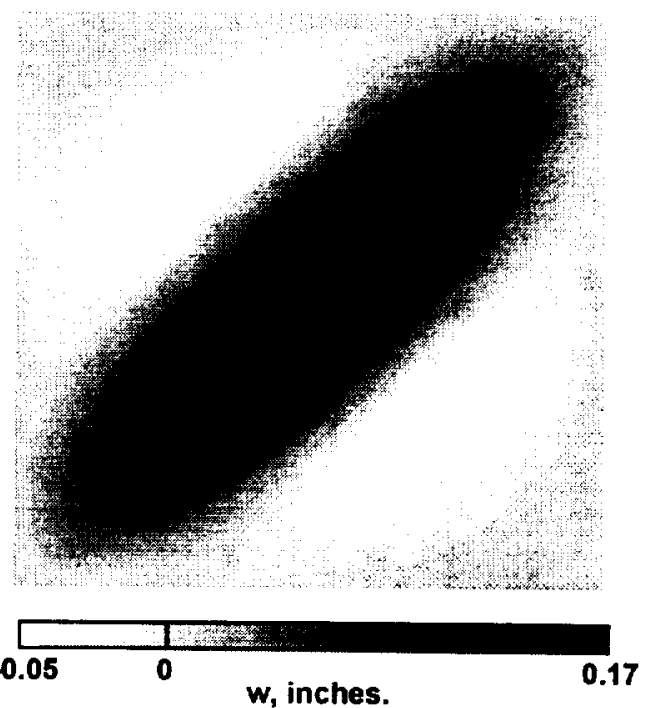

Figure 26- Predicted out-of-plane displacements for $N_{x y}=1000$ lbs/in.

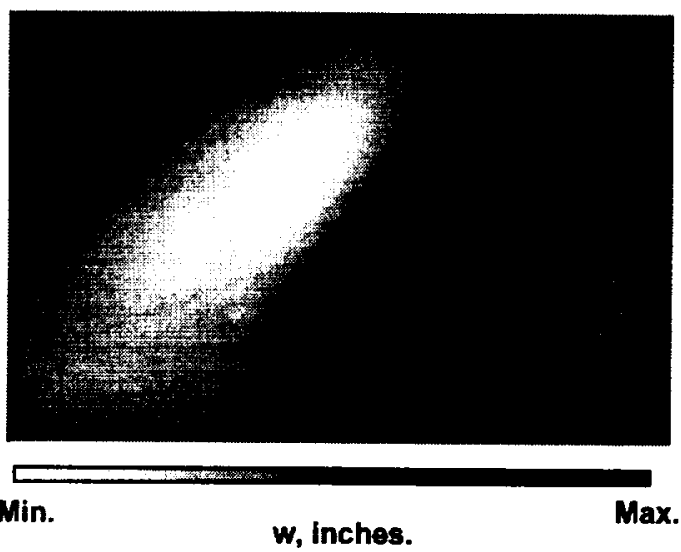

Figure 27. - Predicted linear buckling mode shape.

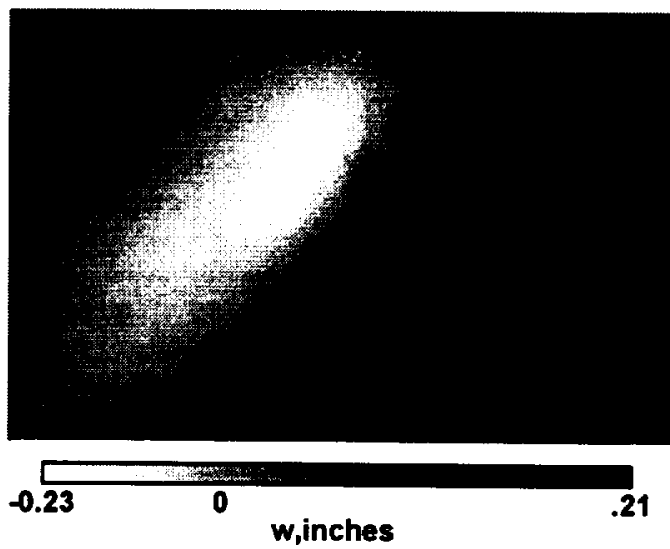

Figure 28. - Predicted out-of-plane displacements for $\mathrm{N}_{\mathbf{x y}}=1000$ lbs/in. 


\section{Panel with a cutout}

The finite element model used for the panel with a cutout is shown in figure 8 . The predicted buckling load from the linear buckling analysis is $300 \mathrm{lbs} / \mathrm{in}$. The predicted first mode shape from a linear buckling analysis has two half-waves at each end bay and is shown in figure 29. The two half-waves are oriented at $45^{\circ}$ and at $30^{\circ}$ to the edge of the panel. The predicted out-of-plane displacement results, $w$, from a nonlinear STAGS analysis

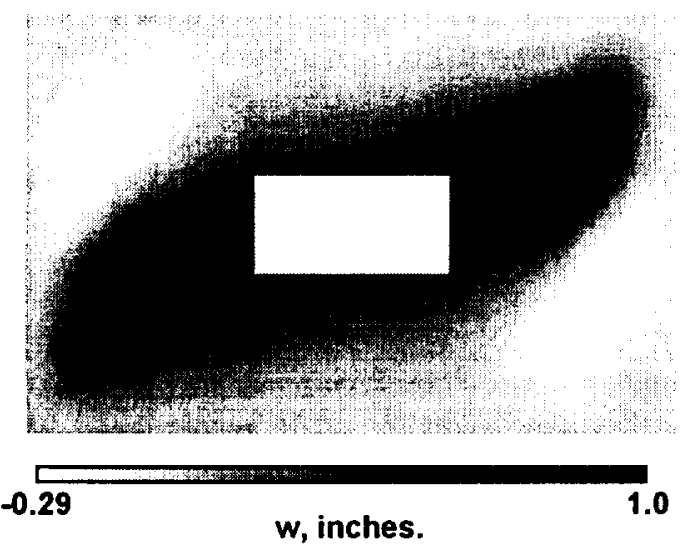

Figure 29. - Predicted linear buckling mode shape.

of the stiffened panel are shown in figure 30 for $N_{x y}=400$ lbs/in. The nonlinear STAGS analysis predicts two halfwaves oriented at approximately $45^{\circ}$ and at $30^{\circ}$ to the edge of the panel as shown in figure 30 for a load of 400 lbs/in. The center bay deflects uniformly out-of-plane as can be observed in figure 30 . The predicted out-of-plane displacements vary from -0.11 inches to 0.05 inches in magnitude. The predicted strain normal to the $45^{\circ}$ buckle pattern in the sandwich skin is shown in figure 31 for the surface ply in the sandwich skin. The strain shown in figure 31 in the stiffeners is across the 1-inch dimension of the stiffener. The strain in the panels varies from 0.003 to $0.004 \mathrm{in} / \mathrm{in}$. The global distribution of the shear stress resultant, $N_{x y}$, is shown in figure 32 for an applied load of $400 \mathrm{lbs} / \mathrm{in}$. The highest value of this shear stress resultant is approximately $644 \mathrm{lbs} / \mathrm{in}$ and is located between the beam reinforcements at each end. The global distribution of the transverse shear stress resultants, $Q_{x}$ and $Q_{y}$, is shown in figure 33 and 34 for an applied shear load, $N_{x y}$, of $400 \mathrm{lbs} / \mathrm{in}$. The maximum value of $Q_{x}$ is at the junction of the sandwich skin and beam reinforcement as shown in figure 33 . The values of $Q_{x}$ vary between $251 \mathrm{lbs} / \mathrm{in}$ and $250 \mathrm{lbs} / \mathrm{in}$. The ends of the beam reinforcement are indicated by the high local value of $Q_{y}$ shown in figure 34 .

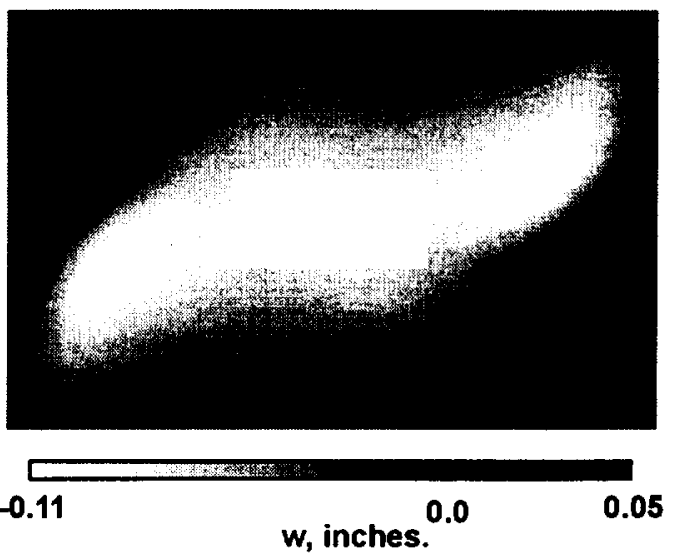

Figure 30. - Predicted out-of-plane displacements for $\mathbf{N}_{\mathrm{xy}}=\mathbf{4 0 0}$ lbs/in.

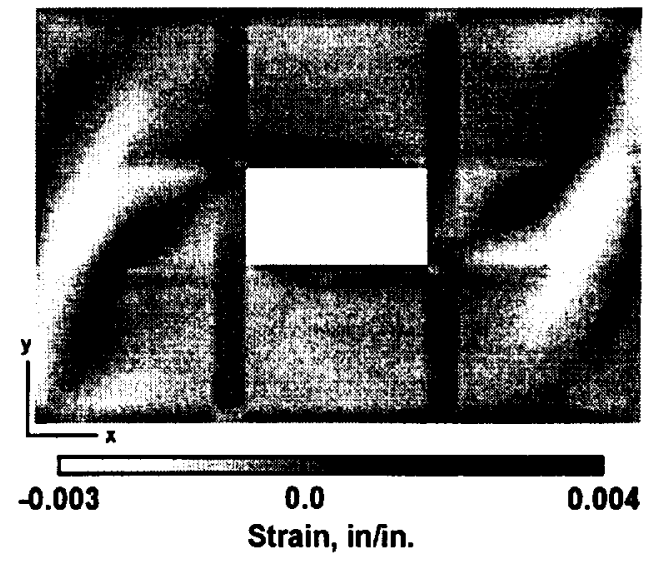

Figure 31. - Predicted strain normal to the $45^{\circ}$ buckle pattern.

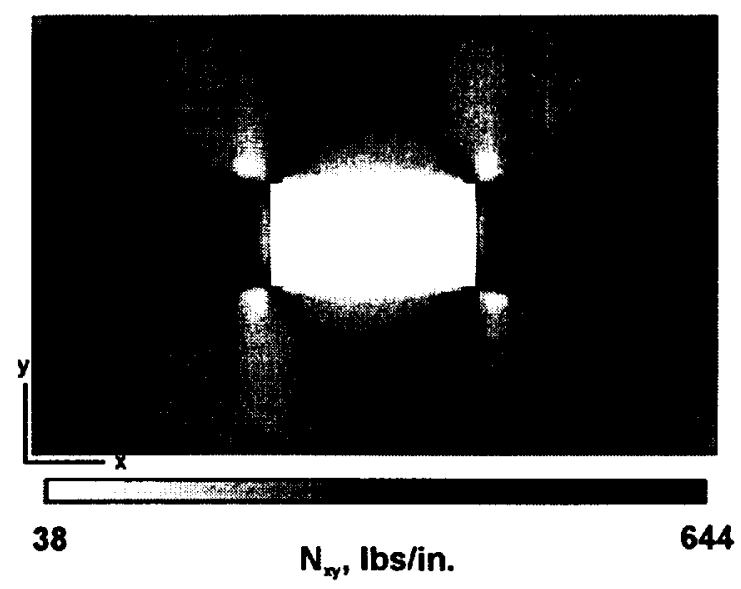

Figure 32. - Distribution of $N_{x y}$ in panel for an applied load of $N_{x y}=400 \mathrm{lbs} / \mathrm{in}$. 


\section{Discussion}

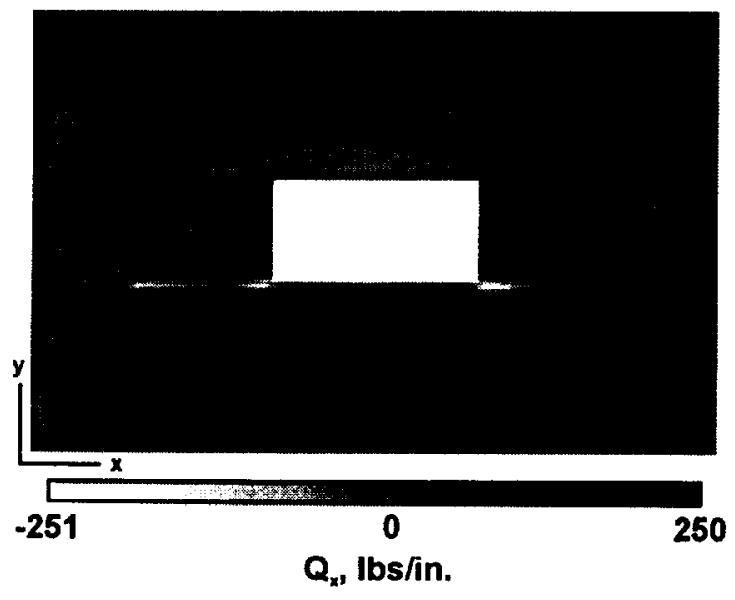

Figure 33. - Distribution of $Q_{x}$ in panel for an applied load of $N_{x y}=\mathbf{4 0 0} \mathrm{lbs} / \mathrm{in}$.

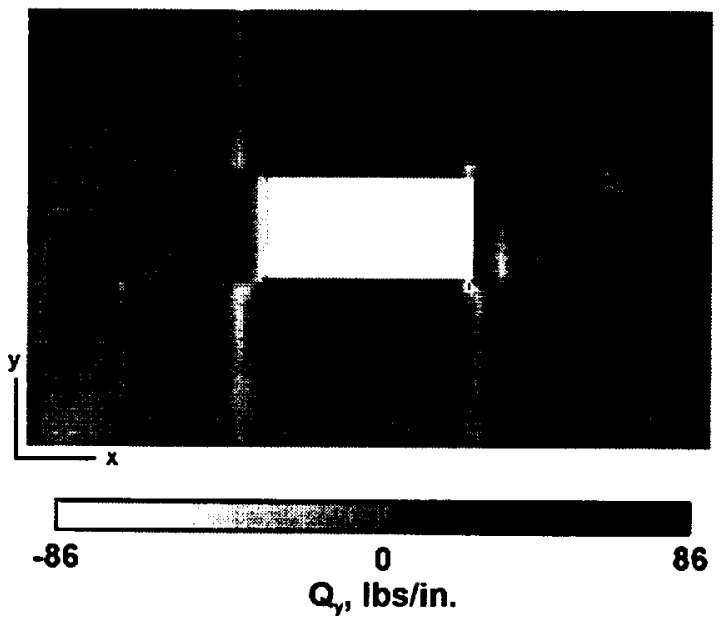

Figure 34. - Distribution of $Q_{y}$ in panel for an applied load of $N_{x y}=400 \mathrm{lbs} / \mathrm{in}$.

\section{Square test panel}

The average of the experimental buckling load for the square panels is equal to $143 \mathrm{lbs} / \mathrm{in}$ and is 53 percent of the predicted buckling load. Comparison of the predicted and experimental out-of-plane displacements shown in figures 9 and 26 indicate that the experimental displacements exceed the predicted results by approximately 0.06 inches or one thickness of the sandwich panel. The average panel failure load is equal to six times the average experimental buckling load.

\section{Panel without a cutout}

The average experimental buckling load of the panels without a cutout is $163 \mathrm{lbs} / \mathrm{in}$ and is 90 percent of the predicted buckling load from the linear analysis. Test mode shapes (figure 12) and analytical mode shapes (figure 28) agree closely. Comparison of the predicted and experimental out-of-plane displacements for LVDT's 1 and 2 are shown in figures 35 and 36, respectively. The nonlinear analysis results predict the panel to stay undeformed until a load of $180 \mathrm{lbs} / \mathrm{in}$, then the panel starts to deflect out-of-plane as shown in figure 35 and 36 by the dashed lines. Apparently, the eccentricity due to the flat stiffeners on one side of the panels is small and does not introduce out-of-plane deformation with load application. The deflection measured by LVDT 1 on Panel B1 follows the same trend as the analysis and its maximum value exceeds the prediction by approximately 0.1 inch at failure. As noted previously, Panel B2 deflected in the opposite direction from Panel B1 and the

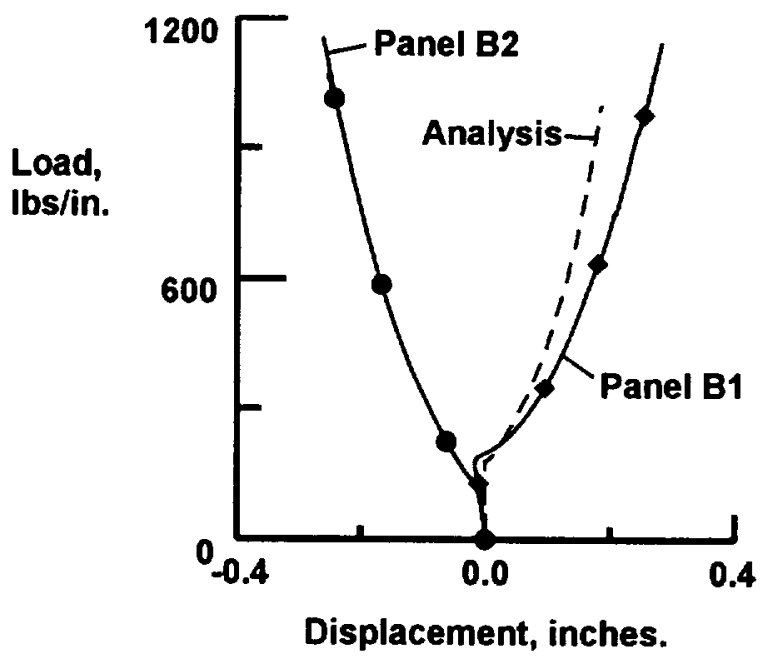

Figure 35. - Comparison of analytical and experimental out-of-plane displacements at the location of LVDT 1 for panels without a cutout. 


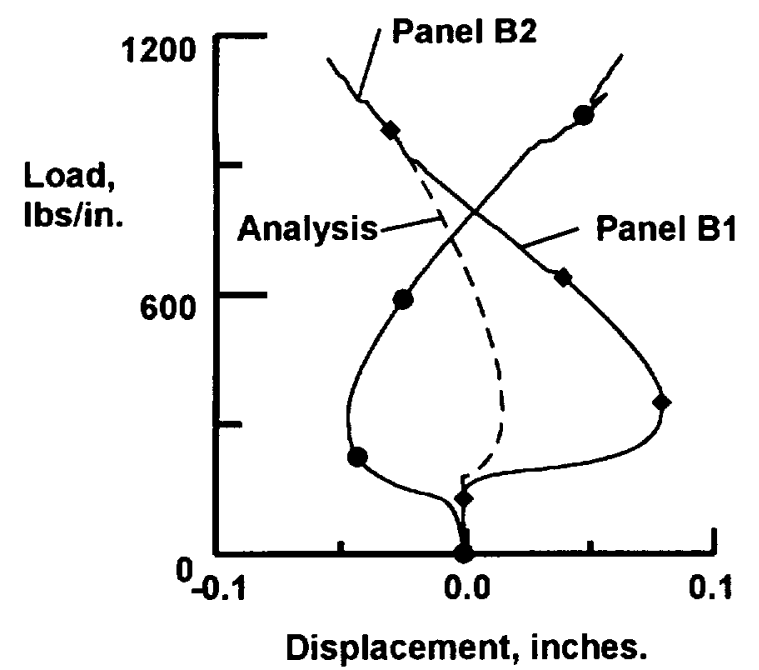

Figure 36. - Comparison of analytical and experimental out-of-plane displacements at the location of LVDT 2 for the panels without a cutout.

magnitude of the displacement is the same, but in the opposite direction. The deflection measured by LVDT 2 exceeds the predicted deflection by approximately 0.06 inches as shown in figure 36 for Panel B1. The deflection measured by LVDT 2 for Panel B2 is also in the opposite direction. The panels did not have any lay-up errors in the sandwich skin which could cause the change in deflection direction. Although the panels have different out-of-plane responses, the panel in-plane shear stiffness is the same. These results suggest that the response of these panels are well understood. Average panel failure load is $1135 \mathrm{lbs} / \mathrm{in}$ which is approximately seven times greater than the average experimental buckling load. The flat stiffeners do increase the buckling load.

\section{Panel with a cutout}

The average experimental buckling load for the panels with a cutout is $250 \mathrm{lbs} / \mathrm{in}$ which is 83 percent of the predicted linear buckling load. The moire fringe pattern for Panel C1 (figure 18) compares well with the predicted global response shown in figure 30 . The moiré fringe pattern for Panel $\mathrm{C} 1$ indicates a uniform out-ofplane deflection along the 6-inch-long side of the cutout which compares well with the predictions. The moiré fringe pattern for Panel C2 (figure 19) indicates a buckle at approximately $45^{\circ}$ to the panel edge as does Panel $\mathrm{Cl}$, but Panel $\mathrm{C} 2$ does not have a buckle at approximately $30^{\circ}$ to the panel edge as does Panel C1. The location of the buckle in the bay between the stringer and the end of the panel on Panel C2 is different when compared to Panel $\mathrm{C} 1$. The moiré fringe pattern along the edge of the 6- inch-long cutout for Panel $\mathrm{C} 2$ indicates a changing out-ofplane deflection while the moiré fringe pattern for Panel $\mathrm{Cl}$ and the predictions indicate a uniform deflection along the cutout. Comparison of the predicted and experimental out-of-plane displacements for LVDT's 2 and 3 are shown in figures 37 and 38 . The nonlinear analysis results indicate that the out-of-plane deflection starts at load initiation, as shown by the dashed lines in figures 37 and 38. The displacements measured by the LVDT's on Panel $\mathrm{C} 2$ follow the trends of the predicted results. Panel failure occurred at an average load of $617 \mathrm{lbs} / \mathrm{in}$ or approximately two and half times the average experimental buckling load. The modes of failure are different for the panels. Panel $\mathrm{C} 1$ failed in a slow progressive manner by pulling the panel apart in the area around the beam reinforcements. This mode of failure is not surprising considering the predicted high shear stress resultant (figure 32) between the beam reinforcements and the predicted transverse shear resultants (figure 33 and 34) around the edges of the beam reinforcement. Panel C2 failed by a single rupture of the skin on the node of the buckle. The different deflection patterns and failure modes have very little affect on the in-plane shear stiffness (figure 24) of the panel. The sharp reentrant corners in the cutouts did not significantly affect the panel response.

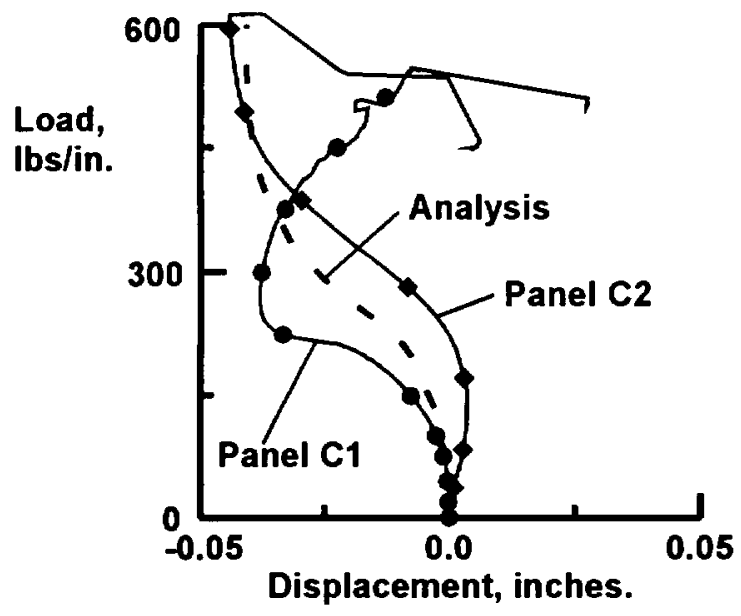

Figure 37. - Comparison of analytical and experimental out-of-plane displacements at the location of LVDT 2 for panels with a cutout. 


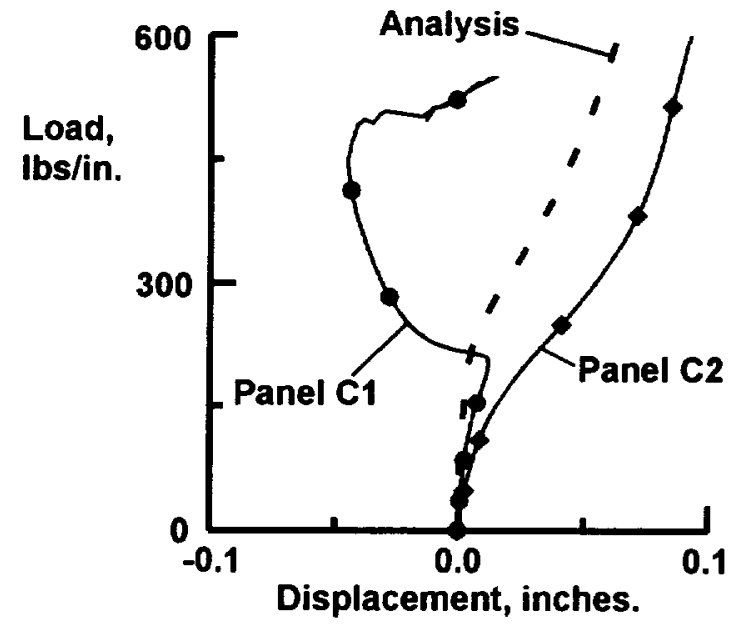

Figure 38. - Comparison of analytical and experimental out-of-plane displacements at the location of LVDT 3 for the panels with a cutout.

\section{Concluding Remarks}

\footnotetext{
A low-cost structurally-efficient minimum-gage shear-panel design concept has been developed that can be used for light helicopters. The shear panel designs are based on an integrally-stiffened syntactic-adhesivestabilized skin concept with an all-bias-ply tape construction for the skins. This sandwich concept is an economical way to increase the bending stiffness of the panel with a minimum weight penalty. The concept of using unidirectional carbon-epoxy tape on a syntactic adhesive co-cured with the skin as a stiffener is an effective concept for improving the buckling strength. The use of pultruded carbon-epoxy rods embedded in a syntactic film adhesive and over-wrapped with a bias-ply carbon-epoxy tape to form a reinforcing beam is a effective method for redistributing load around a rectangular cutout. The buckling strength of the reinforced panels are 83 to 90 percent of the predicted strength from linear analysis. The failure strength of the reinforced panels was 250 to 700 percent of the buckling strength. The experimental deflections exceed the deflections predicted by a nonlinear analysis by approximately one panel thickness. This structurallyefficient shear-panel design exceeds the ultimate strength requirement of $300 \mathrm{lbs} / \mathrm{in}$ by over 100 percent.
}

\section{References}

1. Taylor, R., Nunn, K., and Roger, C., "Material Applications to a Light Helicopter," American Helicopter Society, 49th Annual Forum, May 1993.

2. Bruhn, E. F., Analysis and Design of Flight Vehicle Structures, S. R. Jacobs \& Associates, Inc., 1973.

3. Farley, G. L. and Baker, D. J., "In-plane Shear Test of Thin Panels," Experimental Mechanics, Vol. 23, No. 1, March 1983, pp. 81-88.

4. Brogan, F. A., Rankin, C. C., and Cabiness, H. D., "STAGS Users Manual," Lockheed Palo Alto Research Laboratory, Report LMSC P032594, 1994. 
. 